\title{
Buckling of stainless steel welded I-section columns
}

Stijn Tuezney ${ }^{a}$, Kathleen Lauwens ${ }^{a, b, *}$, Sheida Afshan ${ }^{c}$, Barbara Rossi ${ }^{a, d}$

${ }^{a}$ KU Leuven, Department of Civil Engineering, Belgium

stijn.tuezney@student.kuleuven.be, kathleen.lauwens@kuleuven.be, barbara.rossi@kuleuven.be

${ }^{b}$ Research Foundation Flanders, Belgium

${ }^{c}$ University of Southampton, Department of Civil, Maritime and Environmental Engineering, UK

s.afshan@soton.ac.uk

${ }^{d}$ University of Oxford, Department of Engineering Science, UK

barbara.rossi@new.ox.ac.uk

\section{Abstract}

This paper studies the buckling behaviour and design of welded I-section stainless steel columns. Experimental and numerical structural performance data together with the design methods for stainless steel welded I-section columns available in the literature have been collated and reviewed. A numerical modelling programme including validation and parametric studies has been carried out to supplement the literature experimental and numerical data for the assessment of the existing codified and literature proposed flexural buckling design formulations for stainless steel welded I-section columns. Columns of austenitic, duplex and ferritic stainless steel grades undergoing major axis and minor axis flexural buckling have been investigated. From comparisons with the EN 1993-1-4 (EC3) flexural buckling capacity predictions, it was found that (1) for the austenitic welded I-section columns, the EC3 buckling curve ( $\alpha=0.76$ and $\left.\bar{\lambda}_{0}=0.2\right)$ is suitable for both axes, (2) for the duplex and ferritic grades, the EC3 buckling curve ( $\alpha=0.76$ and $\bar{\lambda}_{0}=0.2$ ) is conservative, and a higher buckling curve with (i) $\alpha=0.49$ and $\bar{\lambda}_{0}=0.2$ for both axes or (ii) $\alpha=0.49$ and $\bar{\lambda}_{0}=0.2$ for minor axis and $\alpha=0.34$ and $\bar{\lambda}_{0}=0.2$ for major axis may be adopted. In addition, comparisons with the recently proposed Continuous Strength Method showed marginally improved strength predictions but with slightly higher scatter.

Keywords: Buckling; Continuous Strength Method; Eurocode; I-section; Reliability assessment; Stainless steel.

\section{Introduction}

The first design guidance for structural stainless steel written in Europe was the 'Design Manual for Structural Stainless Steel', prepared by the Steel Construction Institute (SCI) and published by Euro Inox in 1994 [1]. It formed the basis for the 'ENV 1993-1-4: Design of Steel Structures - Supplementary rules for stainless steel' [2] which was released by the European standards committee CEN in 1996. In 
2006, this pre-standard was converted into EN 1993-1-4 [3], which was subsequently updated in 2015.

34 The 2015 version [3] is the most recent version currently available. The SCI published a fourth edition

35 of the 'Design Manual for Structural Stainless Steel' [4] in 2017 providing the latest research updates

36 on stainless steel design.

37 The Design Manual for Structural Stainless Steel [4] offers an alternative approach known as the 38 Continuous Strength Method (CSM) for determining the cross-sectional resistance of stainless steel 39 structural members. CSM is a deformation-based design approach which uses the cross-section 40 deformation capacity, controlled by the cross-section slenderness, and the strain hardening of the 41 material to predict the capacity of the cross-section. For symmetrical cross-sections, comparisons with 42 the Eurocode approach has shown that the CSM provides more accurate results in the design of low 43 slenderness cross-sections and similar results in the design of higher slenderness cross-sections [4, 5, 6].

44 Following the development of the CSM for the design of structural elements at cross-section level, 45 research on the extension of the method for design at member level is currently ongoing. Recently, 46 Arrayago et al. [7] and [8] presented a CSM approach for flexural buckling design of stainless steel 47 hollow section columns. The proposed method was shown to provide more accurate flexural buckling 48 resistance predictions for stainless steel RHS and SHS columns compared to the EN 1993-1-4 [3] 49 method. The authors recommended that the proposed new CSM approach provides a framework that 50 can be extended to further cross-section types and materials, as well as to other failure modes, such as 51 lateral-torsional buckling and loading conditions, such as axial load plus bending.

52 This paper presents an investigation into the flexural buckling behaviour of stainless steel welded-I 53 section columns. The current codified and literature proposed rules for the design of stainless steel 54 welded-I section compression members is first presented. A comprehensive review of the relevant 55 experimental and numerical studies in the literature has been carried out to collate the pool of available 56 structural performance data on stainless steel welded I-section columns. The collated literature data are 57 supplemented by a new set of numerical data generated in this paper. The data are used to examine the 58 suitability of the EN 1993-1-4 [3] flexural buckling curves and the CSM design approach [8] to 59 accurately predict the flexural buckling resistance of welded stainless steel I-section columns and 60 conduct reliability analysis. 


\section{$2.1 \quad$ European standard}

\subsubsection{Cross-sectional resistance}

EN 1993-1-1 [9] and EN 1993-1-4 [3] use the cross-section classification method to account for the reductions in the load carrying capacity of the cross-section due to local buckling effects, in which the slenderness of the constitutive plate elements of the cross-section are compared with their corresponding specified slenderness limits. The cross-section compression resistance $N_{c, R d}$ of Class 1,2 and 3 crosssections is not affected by local buckling and is taken as the full yield load given by Eq. (1), where $A$ is the gross cross-sectional area and $f_{\mathrm{y}}$ is the yield stress, taken as the $0.2 \%$ proof stress and $\gamma_{\mathrm{M} 0}$ is the partial safety factor for cross-sectional resistance. For Class 4 sections, the cross-section compression resistance is reduced by local buckling and $N_{c, R d}$ is taken as the product of the effective cross-sectional area $A_{\text {eff }}$ and the yield stress $f_{\mathrm{y}}$ as given by Eq. (2).

$$
\begin{array}{ll}
\mathrm{N}_{\mathrm{c}, \mathrm{Rd}}=\mathrm{Af}_{\mathrm{y}} / \gamma_{\mathrm{M} 0} & \text { for Class } 1,2 \text { and } 3 \text { cross-sections } \\
\mathrm{N}_{\mathrm{c}, \mathrm{Rd}}=\mathrm{A}_{\mathrm{eff}} \mathrm{f}_{\mathrm{y}} / \gamma_{\mathrm{M} 0} & \text { for Class } 4 \text { cross-sections }
\end{array}
$$

\subsubsection{Member buckling resistance}

74 EN 1993-1-1 [9] and EN 1993-1-4 [3] describe three modes of instability for compression members, 75 namely flexural buckling, torsional buckling and torsional-flexural buckling. To obtain the member 76 buckling resistance, the code adopts a non-iterative method in which different buckling curves based on 77 the Perry-Robertson formulation are applied for different columns depending on the cross-section shape, 78 production route and axis of buckling. The flexural buckling resistance $N_{\mathrm{b}, \mathrm{Rd}}$ is predicted from, Eq. (3)

79 for Class 1, 2 and 3 sections and Eq. (4) for Class 4 sections [3], where $\chi$ is the reduction factor for 80 flexural buckling mode, $\gamma_{\mathrm{M} 1}$ is the partial safety factor for member resistance and all other parameters $81 \quad$ are as previously defined.

$$
\begin{array}{ll}
\mathrm{N}_{\mathrm{b}, \mathrm{Rd}}=\chi A \mathrm{Af}_{\mathrm{y}} / \gamma_{\mathrm{M} 1} & \text { for Class } 1,2 \text { and } 3 \text { cross-sections } \\
\mathrm{N}_{\mathrm{b}, \mathrm{Rd}}=\chi \mathrm{A}_{\text {eff }} \mathrm{f}_{\mathrm{y}} / \gamma_{\mathrm{M} 1} & \text { for Class } 4 \text { cross-sections }
\end{array}
$$


Table 1. $\alpha$ and $\bar{\lambda}_{0}$ values from EN 1993-1-4 [3].

\begin{tabular}{llll}
\hline Type of buckling mode & Type of member & $\alpha$ & $\bar{\lambda}_{0}$ \\
\hline Flexural & Cold formed open sections & 0.49 & 0.40 \\
Flexural & Hollow sections (welded and seamless) & 0.49 & 0.40 \\
Flexural & Welded open sections (major axis) & 0.49 & 0.20 \\
Flexural & Welded open sections (minor axis) & 0.76 & 0.20 \\
Torsional and torsional-flexural & All members & 0.34 & 0.20 \\
\hline
\end{tabular}
[4] for the design of cold-formed and hot-finished stainless steel square, rectangular and circular hollow section columns. The recommended buckling curves have different $\alpha$ and $\bar{\lambda}_{0}$ parameters for different stainless steel grades, austenitic, duplex and ferritic; this was to account for the effect of the different degrees of nonlinearity of the stress-strain behaviour of the different stainless steel grades on the column buckling strength. The derivation of these buckling curves is reported in Afshan et al. [10]. It is expected that the next revision of EN 1993-1-4 [3] will adopt these new flexural buckling curves. However, the buckling curve parameters for welded open sections remained unchanged in the Design Manual for Structural Stainless Steel [4].

The present paper aims to systematically assess whether the same conclusion as those for hollow sections should be drawn for welded I-section columns and that the parameters $\alpha$ and

$101 \bar{\lambda}_{0}$ currently adopted in EN 1993-1-4 [3], which are respectively equal to 0.76 and 0.20 for minor axis buckling, and 0.49 and 0.20 for major axis buckling should be revised. 


\subsection{Continuous strength method}

104

105

106

107

108

109

110

111

112

113

114

115

116

\subsubsection{Cross-sectional resistance}

The CSM cross-section resistance is determined by first determining the cross-section deformation capacity $\varepsilon_{\mathrm{csm}} / \varepsilon_{\mathrm{y}}$, i.e. the ratio of the maximum attainable strain and the yield strain, by means of a 'base curve', defined by Eq. (8) and (9) for non-slender and slender cross-sections, respectively. The continuous strength method uses the full cross-section slenderness $\bar{\lambda}_{\mathrm{p}}$, and thus takes into account the beneficial effect of element interaction. An elastic, linear hardening model with strain hardening slope $E_{\mathrm{sh}}$ given by Eq. (10) is employed, which is in terms of the yield stress $f_{\mathrm{y}}$, ultimate tensile stress $f_{\mathrm{u}}$, yield stress $\varepsilon_{\mathrm{y}}$, strain at ultimate tensile stress $\varepsilon_{\mathrm{u}}$ and employs four material parameters $\left(C_{1}, C_{2}, C_{3}\right.$ and $\left.C_{4}\right)$, which are defined in Annex D.2 of the Design Manual for Structural Stainless Steel [4].

$$
\begin{array}{ll}
\frac{\varepsilon_{\mathrm{csm}}}{\varepsilon_{\mathrm{y}}}=\frac{0.25}{\bar{\lambda}_{\mathrm{p}}^{3.6}} \text { but } \leq \min \left(15, \frac{\mathrm{C}_{1} \varepsilon_{\mathrm{u}}}{\varepsilon_{\mathrm{y}}}\right) & \text { for } \bar{\lambda}_{\mathrm{p}} \leq 0.68 \\
\frac{\varepsilon_{\mathrm{csm}}}{\varepsilon_{\mathrm{y}}}=\left(1-\frac{0.222}{\bar{\lambda}_{\mathrm{p}}^{1.050}}\right) \frac{1}{\bar{\lambda}_{\mathrm{p}}^{1.050}} & \text { for } \bar{\lambda}_{\mathrm{p}}>0.68 \\
\mathrm{E}_{\mathrm{sh}}=\frac{\mathrm{f}_{\mathrm{u}}-\mathrm{f}_{\mathrm{y}}}{\mathrm{C}_{2} \varepsilon_{\mathrm{u}}-\varepsilon_{\mathrm{y}}} & \text { with } \varepsilon_{\mathrm{u}}=\mathrm{C}_{3}\left(1-\mathrm{f}_{\mathrm{y}} / \mathrm{f}_{\mathrm{u}}\right)+\mathrm{C}_{4}
\end{array}
$$

Following the determination of the cross-section deformation capacity and the strain hardening slope, the cross-section compression resistance $\mathrm{N}_{\mathrm{c}, \mathrm{csm}, \mathrm{Rd}}$ and the cross-section bending resistance $\mathrm{M}_{\mathrm{c}, \mathrm{csm}, \mathrm{Rd}}$ may be determined from Eqs. (11) and (12), respectively, where $\mathrm{W}_{\mathrm{el}}$ and $\mathrm{W}_{\mathrm{pl}}$ are the elastic and plastic section moduli, respectively and all other parameters are as previously defined.

$$
\begin{aligned}
& \mathrm{N}_{\mathrm{c}, \mathrm{csm}, \mathrm{Rd}}=\left\{\begin{array}{cc}
\frac{\mathrm{Af}_{\mathrm{y}}}{\gamma_{\mathrm{M} 0}}\left[1+\frac{\mathrm{E}_{\mathrm{sh}}}{\mathrm{E}}\left(\frac{\varepsilon_{\mathrm{csm}}}{\varepsilon_{\mathrm{y}}}-1\right)\right] & \text { for } \bar{\lambda}_{\mathrm{p}} \leq 0.68 \\
\frac{\mathrm{A}}{\mathrm{f}_{\mathrm{y}} \gamma_{\mathrm{M} 0}}\left(\frac{\varepsilon_{\mathrm{csm}}}{\varepsilon_{\mathrm{y}}}\right) & \text { for } \bar{\lambda}_{\mathrm{p}}>0.68
\end{array}\right. \\
& \mathrm{M}_{\mathrm{c}, \mathrm{csm}, \mathrm{Rd}}=\left\{\begin{array}{cc}
\frac{\mathrm{W}_{\mathrm{pl}} \mathrm{f}_{\mathrm{y}}}{\gamma_{\mathrm{M} 0}}\left[1+\frac{\mathrm{E}_{\mathrm{sh}}}{\mathrm{E}} \frac{\mathrm{W}_{\mathrm{el}}}{\mathrm{W}_{\mathrm{pl}}}\left(\frac{\varepsilon_{\mathrm{csm}}}{\varepsilon_{\mathrm{y}}}-1\right)-\left(1-\frac{\mathrm{W}_{\mathrm{el}}}{\mathrm{W}_{\mathrm{pl}}}\right) /\left(\frac{\varepsilon_{\mathrm{csm}}}{\varepsilon_{\mathrm{y}}}\right)^{\alpha}\right] & \text { for } \bar{\lambda}_{\mathrm{p}} \leq 0.68 \\
\frac{\mathrm{W}_{\mathrm{el}} \mathrm{f}_{\mathrm{y}}}{\gamma_{\mathrm{M} 0}}\left(\frac{\varepsilon_{\mathrm{csm}}}{\varepsilon_{\mathrm{y}}}\right) & \text { for } \bar{\lambda}_{\mathrm{p}}>0.68
\end{array}\right.
\end{aligned}
$$

\subsubsection{Member buckling resistance}

In 2015, Ahmed et al. [11] made a first proposal for a CSM based approach for the flexural buckling resistance of columns. The proposed method is of the same form as the EN 1993-1-4 [3] buckling curves, 
but employs the following modifications: (1) the CSM predicted local buckling stress of the cross121 section $f_{\text {csm }}$ instead of the yield stress $f_{\mathrm{y}}$ is used throughout, (2) the full cross-sectional area is used for 122 all cross-section slendernesses and (3) different buckling curves for columns with different cross-section 123 slenderness $\bar{\lambda}_{\mathrm{p}}$ are employed. The proposed buckling curves have different limiting non-dimensional 124 slenderness ratio $\bar{\lambda}_{0}$, which were appropriately calibrated for varying cross-sectional slenderness $\bar{\lambda}_{\mathrm{p}}$, to allow for the observed effects of local cross-section slenderness on the flexural buckling resistance, but employ a constant imperfection factor $\alpha$. In 2018, Ahmed et al. [12] proposed a revised CSM method (Eq. (14) to (22) in [12]), in which a modified non-dimensional slenderness $\bar{\lambda}_{\mathrm{m}}$ is employed in the $\phi_{\mathrm{csm}}$, $\chi_{\mathrm{csm}}$ and the generalised imperfection factor $\eta$. Both methods give promising results, but only one stainless steel grade, an austenitic one, was considered to calibrate the methods.

In 2020, Arrayago et al. [8] proposed a CSM based approach for the flexural buckling resistance of columns, an overview of which is provided hereafter. Within the proposed CSM member design framework, the flexural buckling resistance $N_{\mathrm{b}, \mathrm{csm}, \mathrm{Rd}}$ is determined by Eq. (13), where $\chi_{\mathrm{csm}}$ is the CSM flexural buckling reduction factor and $N_{\mathrm{c}, \mathrm{csm}, \mathrm{Rk}}$ is the characteristic CSM predicted cross-section compression resistance. The $\chi_{\mathrm{csm}}$ factor is determined from Eq. (14), where the CSM defined member slenderness $\bar{\lambda}_{\mathrm{csm}}$ and the generalised imperfection factor $\eta_{\mathrm{csm}}$ are employed. The CSM member slenderness $\bar{\lambda}_{\text {csm }}$ is defined as the square root of the ratio of the characteristic CSM predicted crosssection compression resistance $N_{\mathrm{c}, \mathrm{csm}, \mathrm{Rk}}$ and the critical elastic buckling load $N_{\mathrm{cr}}$ as given by Eq. (15). EN 1993-1-4 [3], $e_{0, \mathrm{csm}} / e_{0, \mathrm{el}, \mathrm{EN}}$ is the ratio between the CSM and EC3 equivalent imperfection amplitudes, which is determined by Eq. (17), $\mathrm{f}_{\mathrm{c}, \mathrm{csm}}=\mathrm{N}_{\mathrm{c}, \mathrm{csm}, \mathrm{Rk}} / \mathrm{A}, \mathrm{M}_{\mathrm{c}, \mathrm{csm}, \mathrm{Rk}}$ is the characteristic CSM cross-section bending resistance and all other parameters are as previously defined. In Eq. (17) the coefficient $\mathrm{C}_{5}=1+0.68 \mathrm{C}_{6}$ and the coefficient $\mathrm{C}_{6}=1.2\left(\mathrm{f}_{\mathrm{u}} / \mathrm{f}_{\mathrm{y}}\right)$. For slender cross-section $\left(\bar{\lambda}_{\mathrm{p}}>0.68\right)$ members, the CSM imperfection factor $\alpha_{\mathrm{csm}}$ is equal to the EN 1993-1-4 [3] imperfection factor $\alpha_{\mathrm{EN}}$, which makes the approach equivalent to the EN 1993-1-4 [3] procedure with fully-effective crosssection properties, but with local buckling being taken into account through the cross-section deformation capacity $\varepsilon_{\mathrm{csm}} / \varepsilon_{\mathrm{y}}$ rather than the effective width method.

$$
\begin{aligned}
& \mathrm{N}_{\mathrm{b}, \mathrm{csm}, \mathrm{Rd}}=\chi_{\mathrm{csm}} \mathrm{N}_{\mathrm{c}, \mathrm{csm}, \mathrm{Rk}} / \gamma_{\mathrm{M} 1} \\
& \chi_{\mathrm{csm}}=\frac{1}{\phi_{\mathrm{csm}}+\sqrt{\phi_{\mathrm{csm}}{ }^{2}-\bar{\lambda}_{\mathrm{csm}}{ }^{2}}} \leq 1 \text { where } \phi_{\mathrm{csm}}=0.5\left(1+\eta_{\mathrm{csm}}+\bar{\lambda}_{\mathrm{csm}}{ }^{2}\right) \text { and } \eta_{\mathrm{csm}}=\alpha_{\mathrm{csm}}\left(\bar{\lambda}_{\mathrm{csm}}-\bar{\lambda}_{0}\right) \\
& \bar{\lambda}_{\mathrm{csm}}=\sqrt{\frac{\mathrm{N}_{\mathrm{c}, \mathrm{csm}, \mathrm{Rk}}}{\mathrm{N}_{\mathrm{cr}}}}
\end{aligned}
$$




$$
\begin{aligned}
& \alpha_{\mathrm{csm}}=\alpha_{\mathrm{EN}} \frac{\mathrm{e}_{0, \mathrm{csm}}}{\mathrm{e}_{0, \mathrm{el}, \mathrm{EN}}} \sqrt{\frac{\mathrm{f}_{\mathrm{y}}}{\mathrm{f}_{\mathrm{c}, \mathrm{csm}}}} \frac{\mathrm{f}_{\mathrm{c}, \mathrm{csm}} \mathrm{W}_{\mathrm{el}}}{\mathrm{M}_{\mathrm{c}, \mathrm{csm}, \mathrm{Rk}}} \\
& \frac{\mathrm{e}_{0, \mathrm{csm}}}{\mathrm{e}_{0, \mathrm{el}, \mathrm{EN}}}=\left\{\begin{array}{cc}
\mathrm{C}_{5}-\mathrm{C}_{6} \bar{\lambda}_{\mathrm{p}} & \text { for } \bar{\lambda}_{\mathrm{p}} \leq 0.68 \\
1 & \text { for } \bar{\lambda}_{\mathrm{p}}>0.68
\end{array}\right.
\end{aligned}
$$

Arrayago et al. [8] showed that this approach provides improved predictions for RHS and SHS columns with stocky cross-sections, and similar results, whilst having a less complicated design process, for RHS and SHS columns with slender cross-section compared to the EN 1993-1-4 [3] procedure.

The present paper applies a CSM approach based on Ahmed et al.'s proposal [11], but using the EN1993-1-4 buckling curves instead of the calibrated curves, herein denoted as CSM1 and the CSM approach proposed by Arrayago et al. [8], herein denoted as CSM2, on I-section columns and compares the predictions to the predictions from the EN 1993-1-4 [3] approach.

\section{Collection of existing experimental and numerical work on member buckling and comparisons with EC3 and CSM predictions}

\subsection{Collection of existing work}

The first reported data on stainless steel welded-I section columns, dating back to 1995, are from Bredenkamp and Van Den Berg [13], where thirteen minor axis flexural buckling tests on ferritic EN 1.4512 columns were reported. Their results showed that the design procedures available at that time were unable to provide accurate results for long columns and that, since inelastic behaviour of the members starts at low stresses, the effect of material non-linearity should be considered when predicting the strength of stainless-steel built-up columns.

A major research project was started by the European Coal and Steel Community in 1997 to further develop and refine the design codes for stainless steel structures. Part of the investigation was on the flexural buckling behaviour of welded I-section columns. Twelve austenitic EN 1.4301 and three duplex EN 1.4462 columns were tested [14]. These tests, along with the tests carried out by Bredenkamp and Van Den Berg [13] and the results from the Steel Construction Institute (austenitic EN 1.4404) [14], were compared to the ENV 1993-1-4 (1996) design predictions [2]. It was concluded that the ENV 1993-1-4 buckling curve, with $\alpha=0.76$ and $\bar{\lambda}_{0}=0.20$, shows good agreement with the test results of the austenitic and ferritic columns, but gives conservative results for the tested duplex columns. The authors [14] concluded that the lower residual stresses that are present in the duplex stainless steel sections, compared to austenitic and ferritic sections, resulted in higher measured column strength in the tests. 
In 2015, Yuan et al. [15] investigated the local-overall interactive buckling behaviour of stainless steel columns. A total of ten, five austenitic EN 1.4301 and five duplex EN 1.4462, columns were tested. All tested columns failed by local-overall interactive buckling about the minor axis. The results were used for the validation of finite element (FE) models and to perform a parametric study. The results showed that the 2006 version of EN 1993-1-4 [3] underestimates the strength of the investigated austenitic and duplex columns. Yuan et al. [15] proposed modified imperfection factors and plateau lengths on the basis of their numerical and experimental data. However, the 2015 update of EN 1993-1-4 [3] was not compared against the Yuan et al. tests.

Yang et al. [16] investigated austenitic EN 1.4301 and duplex EN 1.4462 stainless steel welded I-section columns in 2016. Eleven columns of each grade, covering a wide range of member slenderness values, were tested. All tests were modelled by FE analysis, although no parametric study was performed in the paper. The laboratory results were used to assess the applicability of EN 1993-1-4 (2006) [3], where it was shown that the design code yields conservative predictions. The flexural buckling design provisions of the 2015 version of the EN 1993-1-4 [3] is the same as its previous version meaning that these conclusions are still valid today.

No test data on laser-welded stainless steel long columns was available prior to Gardner et al.'s research [17]. In their study, twenty two flexural buckling tests on laser-welded I-section columns were performed. All columns were made of austenitic EN 1.1307, EN 1.4571 and 1.4404 stainless steels. Residual stress measurements were taken and it was observed that the magnitudes of the residual stresses in the laser-welded sections are lower than those in conventionally-welded sections. This can be explained by the lower heat input of laser-welding, compared to more commonly used welding procedures. The authors then proposed a model for residual stresses induced by laser-welding on austenitic stainless steel grades. Bu and Gardner reported a parametric study on conventional and laserwelded stainless steel I-sections in [18]. Laboratory tests from Burgan et. al [19], Yang et al. [16] and Gardner et al. [17] were successfully modelled. Upon validation of the modelling technique, parametric studies were also performed and compared to the design provisions for austenitic stainless steel columns. A total of 480 simulations were conducted. For each axis, 120 columns with laser-welded residual stresses and 120 columns with conventional-welded residual stresses were modelled. The results showed that the current EN 1993-1-4 [3] buckling curves for major and minor axes buckling are applicable to the conventionally-welded austenitic stainless steel columns. For laser-welded columns, an improved buckling curve ( $\alpha=0.60$ and $\bar{\lambda}_{0}=0.20$ ) was proposed for minor axis buckling and adoption of the current buckling curve ( $\alpha=0.49$ and $\bar{\lambda}_{0}=0.20$ ) was proposed for major axis buckling.

Ahmed et al. [12] performed a testing program on welded stainless steel I-section columns. Tensile tests and residual stress and geometric imperfection measurements were performed prior to testing the columns. Sixteen columns made of austenitic EN 1.4404 and welded using the tungsten inert gas (TIG) procedure were tested under minor axis buckling. Following the laboratory tests, FE models were 
developed to simulate all sixteen tests. Upon validation of the models, parametric studies were

211 performed to assess the reliability level of the current design provisions. Ahmed et al.'s results (Figure

21238 in [12]) indicated that the Eurocode 3 (2015) [3] provisions for austenitic stainless steel columns of

213 slenderness lower than 0.5 are unsafe. That is in contradiction with Gardner et al. [18]. More specifically,

214 the residual stresses were more detrimental for the minor axis tests than for the major axis tests due to

215 the combination of the maximum compressive stresses and the residual stresses in the flanges. In contrast

216 to minor axis buckling, where the maximum compressive stresses occur at the flange tips, the full flange

217 is subjected to compression for major axis buckling, which is not disturbing the self-equilibrium of the

218 residual stresses. Based on their results, new buckling curves for the CSM were proposed as presented

219 in Section 2.2.2.

\subsection{Comparison with EC3 and the CSM predictions}

The test and FE data collected from the studies presented in Section 3.1 were used to examine the accuracy of the EN 1993-1-4 [3] and CSM [8] [11] flexural buckling design resistance provisions for stainless steel welded I-section columns. Figure 1 shows the variation of the EC3 predicted-to-test strength ratios for (a) the minor axis and (b) the major axis flexural buckling data. The comparison results in terms of the mean and the coefficient of variation $(\mathrm{COV})$ of the predicted-to-test strength ratios for the minor and major axis flexural buckling are also reported in Table 2 and Table 3, respectively.

Most of the works in Section 3.1 suggested that the EN 1993-1-4 [3] predictions are generally conservative, which is also confirmed by the comparison results in Table 2 and Table 3 and Figure 1. However, as the results of Ahmed et al.'s [12] and Bu and Gardner [18] show, the Eurocode 3 [3] provisions for austenitic stainless steel columns in the low and intermediate slenderness range yield unsafe predictions for the major axis buckling resistance as shown in Figure 1, even though yielding conservative results predictions on average over the full buckling range. The duplex columns of Burgan et al. [19] and the austenitic columns of Yang et al. [16] all have relatively low slendernesses, which is the reason why the mean predicted-to-test strength ratio is higher than 1.

Bredenkamp and Van Den Berg [13] suggested that the material non-linearity should be considered when predicting the strength of stainless-steel built-up columns, which is why the CSM approach, as observed herein, gives better estimations of the flexural buckling resistance, though with slightly higher COV. Ahmed et al. have shown in [11] and [12] that CSM rules are dependent on the cross-sectional slenderness and have proposed techniques of taking this dependency into account. Furthermore, Burgan et al. [19] noticed that the difference in the residual stress distributions of the different stainless steel families may necessitate different design rules. The Design Manual for Structural Stainless Steel [4] is already proposing different imperfection factors for different stainless steel grade for hollow section 
243 columns. However, the need for this for the design of I-section columns has not yet been investigated 244 thoroughly.

245 Table 2. Summary of literature data on minor axis buckling of welded I-section columns and comparisons with design predictions (results of laser-welded columns are denoted by an asterisk).

\begin{tabular}{|c|c|c|c|c|c|c|c|c|}
\hline \multirow[b]{2}{*}{ Reference } & \multirow[b]{2}{*}{ Data } & \multirow[b]{2}{*}{ Grade(s) } & \multicolumn{2}{|c|}{$\mathrm{N}_{\mathrm{EC} 3} / \mathrm{N}_{\mathrm{data}}$} & \multicolumn{2}{|c|}{$\mathrm{N}_{\text {CSM1 }} / \mathrm{N}_{\text {data }}$} & \multicolumn{2}{|c|}{$\mathrm{N}_{\mathrm{CSM} 2} / \mathrm{N}_{\text {data }}$} \\
\hline & & & Mean & $\mathrm{COV}$ & Mean & $\mathrm{COV}$ & Mean & $\mathrm{COV}$ \\
\hline [13] & 13 Test results & EN 1.4512 & 0.672 & 0.160 & 0.672 & 0.160 & 0.670 & 0.160 \\
\hline [19] & 6 Test results & EN 1.4301 & 0.965 & 0.091 & 1.012 & 0.093 & 0.990 & 0.096 \\
\hline [16] & 6 Test results & EN 1.4301 & 0.825 & 0.055 & 0.853 & 0.060 & 0.824 & 0.064 \\
\hline [16] & 6 Test results & EN 1.4462 & 0.759 & 0.071 & 0.764 & 0.073 & 0.782 & 0.076 \\
\hline [17] & 14 Test results $*$ & $\begin{array}{l}\text { EN 1.4307, EN 1.4571, } \\
\text { EN 1.4404 }\end{array}$ & 0.811 & 0.077 & 0.892 & 0.090 & 0.826 & 0.104 \\
\hline [18] & 98 FEM results & EN 1.4571 & 0.912 & 0.038 & 0.957 & 0.065 & 0.933 & 0.050 \\
\hline [18] & 99 FEM results * & EN 1.4571 & 0.864 & 0.020 & 0.906 & 0.060 & 0.884 & 0.051 \\
\hline [12] & 16 Test results & EN 1.4404 & 0.926 & 0.022 & 0.958 & 0.051 & 0.933 & 0.043 \\
\hline [12] & 375 FEM results & EN 1.4404 & 0.92 & 0.06 & - & - & - & - \\
\hline
\end{tabular}

Table 3. Summary of literature data on major axis buckling of welded I-section columns and comparisons with design predictions (results of laser-welded columns are denoted by an asterisk).

\begin{tabular}{llllllllll}
\hline & & & \multicolumn{2}{c}{$\mathrm{N}_{\mathrm{EC} 3} / \mathrm{N}_{\text {data }}$} & \multicolumn{2}{c}{$\mathrm{N}_{\text {CSM1 }} / \mathrm{N}_{\text {data }}$} & \multicolumn{2}{c}{$\mathrm{N}_{\text {CSM2 }} / \mathrm{N}_{\text {data }}$} \\
Reference & Data & Grade(s) & Mean & COV & Mean & COV & Mean & COV \\
\hline$[19]$ & 6 Test results & EN 1.4301 & 0.996 & 0.050 & 1.056 & 0.052 & 0.981 & 0.060 \\
{$[19]$} & 3 Test results & EN 1.4462 & 1.013 & 0.007 & 1.029 & 0.009 & 1.006 & 0.012 \\
{$[16]$} & 5 Test results & EN 1.4301 & 1.006 & 0.052 & 1.058 & 0.053 & 0.963 & 0.061 \\
{$[16]$} & 5 Test results & EN 1.4462 & 0.895 & 0.073 & 0.903 & 0.076 & 0.886 & 0.077 \\
{$[17]$} & 8 Test results * & EN 1.4307, EN 1.4571 & 0.790 & 0.038 & 0.909 & 0.072 & 0.803 & 0.078 \\
{$[18]$} & 102 FEM results & EN 1.4571 & 0.942 & 0.035 & 0.988 & 0.065 & 0.923 & 0.070 \\
{$[18]$} & 102 FEM results * EN 1.4571 & 0.935 & 0.046 & 0.980 & 0.078 & 0.916 & 0.082 \\
{$[12]$} & 375 FEM results & EN 1.4404 & 0.95 & 0.05 & - & - & - & - \\
\hline
\end{tabular}




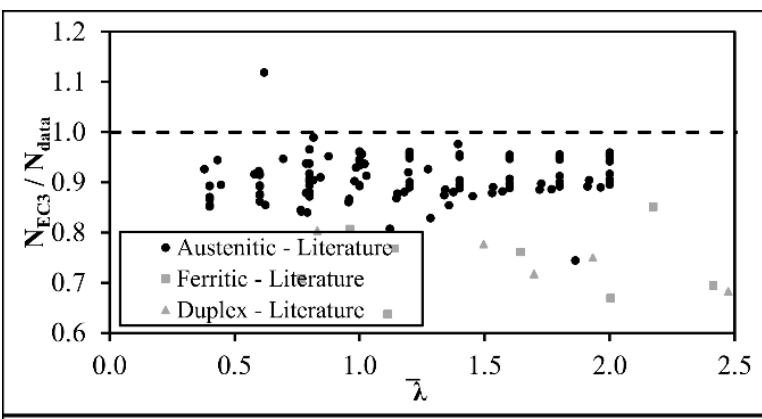

(a)

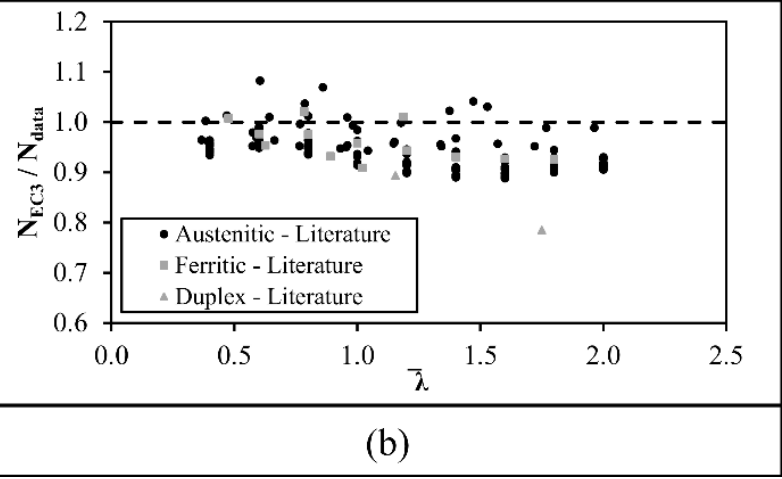

(b)

Figure 1. Results from (a) minor and (b) major axis flexural buckling data - European predictions.

\section{FE Modelling and parametric study}

\subsection{Description of existing numerical work on stainless steel I-section columns}

Table 4 presents the selection of literature numerical modelling studies on stainless steel I-section columns which are reviewed in this section. A summary of the important features of the models is reviewed and discussed. All modelling studies used the commercial FE-package Abaqus except in Yang et al. $[16,20]$ where the analysis programme Ansys was employed.

Table 4. Reference models of stainless steel columns.

\begin{tabular}{ll}
\hline Reference & Modelled structure \\
\hline Becque and Rasmussen (2009) [21] & $\begin{array}{l}\text { Cold-formed I-section long columns, local-overall } \\
\text { interactive buckling } \\
\text { Welded I-section long columns, local-overall } \\
\text { interactive buckling } \\
\text { Yuan et al. (2015) [15] }\end{array}$ \\
Yelded I-section long columns, flexural buckling \\
Ahmed and Ashraf (2018) [12] & Welded I-section long columns, flexural buckling \\
Bu and Gardner (2019) [18] & Welded I-section long columns, flexural buckling
\end{tabular}

\subsubsection{Boundary conditions, element type and analysis technique}

The FE models developed in Abaqus used the S4R shell elements. The non-linear analysis was carried out with the RIKS-method [22]. This allows effective solutions to be found for unstable problems in which unloading occurs, such as the post-buckling behaviour of columns [23, 24, 22]. Boundary conditions for stub columns can be created by restraining all degrees of freedom of all nodes on both ends, except for the axial translation at the loaded end. For long columns with pin-ended boundary conditions, identical conditions are usually applied with the exception of the rotation about the relevant axis of buckling, which is set free at both ends [23, 24]. 
All studies presented in Table 4 used these boundary conditions. Theofanous et al. [25, 26], Zhao et al. [27], Yuan et al. [5], Ahmed et al. [12] and Bu et al. [18] used a reference point (the cross-section centroid) to which some or all of the degrees of freedom of the nodes of the end cross-section are coupled. Then, the boundary conditions are applied to the reference points. By placing the reference point at a given offset of the cross-section centroid, some authors applied the load with a certain eccentricity. Theofanous et al. [25] reported that kinematic coupling of lateral translational degrees of freedom in the end cross-section induced an extra imperfection due to the end cross-section not being able to expand due to Poisson's effect. This causes errors in the post-buckling load-displacement path, though the ultimate load and displacement prior to buckling could correctly be predicted. For this reason, only the rotations and axial displacement for long columns and the axial displacement for stub columns were coupled [25, 26]. However, Yuan et al. [15], Zhao et al. [27], Ahmed et al. [28] and Bu et al. [18] did couple all degrees of freedom to the relevant reference point.

\subsubsection{Material modelling}

The stress-strain behaviour of stainless steel is different from that of carbon steel. Carbon steel has a

280 sharply defined yield point. Stainless steel, on the contrary, has no such yield point and the yield strength 281 is conventionally defined as the nominal stress at $0.2 \%$ plastic strain. The stress-strain curve departs 282 from linearity at small strains prior to the attainment of the conventional proof stress. Additionally, 283 considerable strain hardening occurs [4] at higher strains. Figure 2 shows typical stress-strain curves for 284 three commonly used types of stainless.

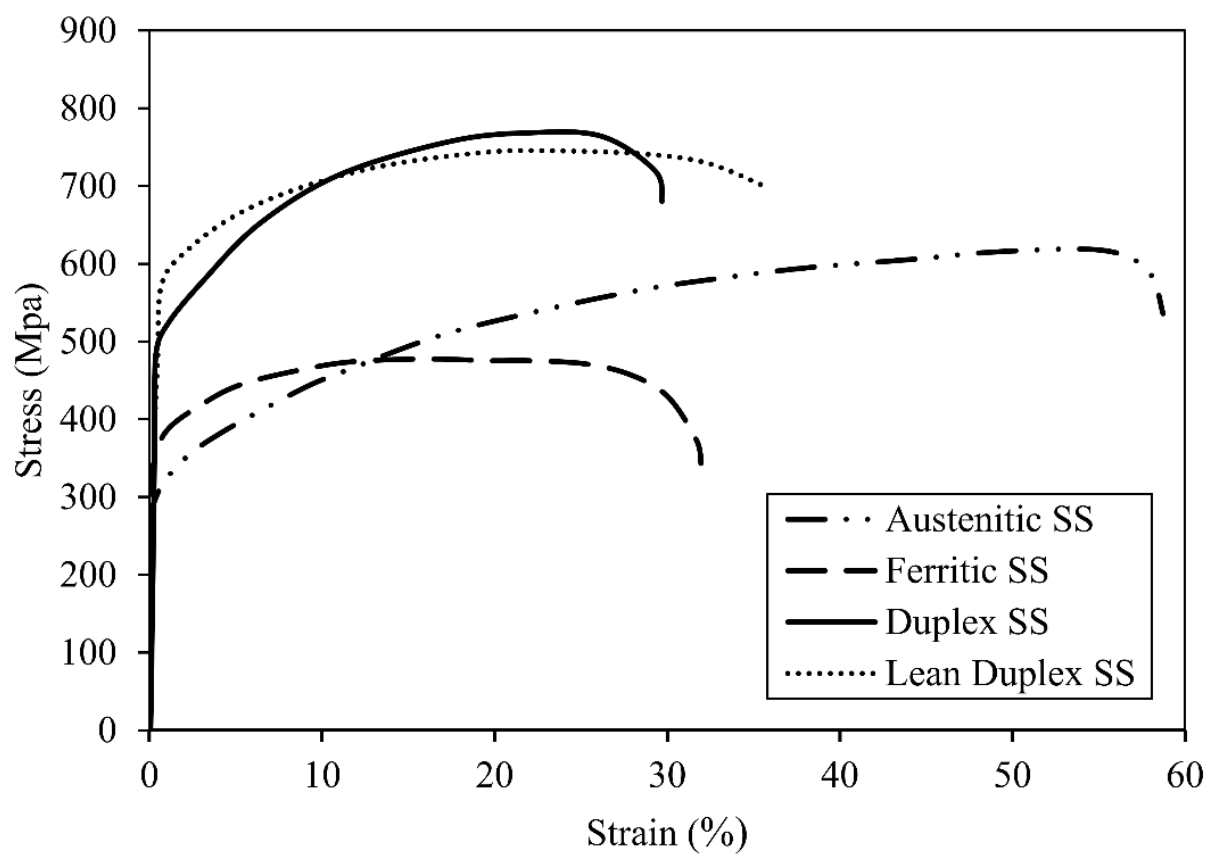

Figure 2. Typical stress-strain curves for stainless steel compared to S355 and S690 carbon steel [29]. 
The nonlinear stress-strain behaviour of stainless steel is typically modelled using a derivation of the

288 Ramberg-Osgood equation [23, 24]. Hill [30] modified the original Ramberg-Osgood equation, 289 developed for modelling of aluminium stress-strain response, for stainless steel. This model has since 290 been modified several times to improve its accuracy and range of applicability. Mirambell and Real [31] 291 proposed a two-stage model with different equations before and after the yield stress point, to describe the full-range stress-strain response of stainless steels. Rasmussen [32] proposed further modifications to the two-stage model. Eq. (18) gives the two-stage Ramberg-Osgood model adopted in Annex C of the EN 1993-1-4 [3], where $f$ and $\varepsilon$ are stress and strain, respectively, $E_{0}$ is the Young's Modulus, $f_{0.2}$ is the $0.2 \%$ proof stress, $f_{\mathrm{u}}$ is the ultimate tensile stress, $\varepsilon_{\mathrm{u}}$ is the strain at the ultimate tensile stress, $E_{0.2}$ is the tangent modulus at $0.2 \%$ proof stress and $n$ and $m$ are the model parameters.

$$
\left\{\begin{array}{c}
\varepsilon=\frac{\mathrm{f}}{\mathrm{E}_{0}}+0.002\left(\frac{\mathrm{f}}{\mathrm{f}_{0.2}}\right)^{\mathrm{n}} ; \text { for } \mathrm{f} \leq \mathrm{f}_{0.2} \\
\varepsilon=\frac{\mathrm{f}-\mathrm{f}_{0.2}}{\mathrm{E}_{0.2}}+\varepsilon_{\mathrm{u}}\left(\frac{\mathrm{f}-\mathrm{f}_{0.2}}{\mathrm{f}_{\mathrm{u}}-\mathrm{f}_{0.2}}\right)^{\mathrm{m}}+\varepsilon_{0.2} ; \text { for } \mathrm{f}_{0.2}<\mathrm{f} \leq \mathrm{f}_{\mathrm{u}}
\end{array}\right.
$$

Arrayago et al. [33] gathered over 600 tensile test results, based on which, predictive equations for the Ramberg-Osgood model parameters $n$ and $m$, the $0.2 \%$ proof stress-to-ultimate stress ratio $f_{0.2} / f_{u}$ and the strain at ultimate tensile stress $\varepsilon_{u}$ were proposed, as given by Eq. (19) to (22), respectively. The proposed equations are specific to the stainless steel grade and provide more accurate representation of the stressstrain response compared with those provided in Annex C of EN 1993-1-4 [3].

$$
\begin{aligned}
& \mathrm{n}=\frac{\ln (4)}{\ln \left(\frac{\mathrm{f}_{0.2}}{\mathrm{f}_{0.05}}\right)} \\
& \mathrm{m}=1+2.8 \frac{\mathrm{f}_{0.2}}{\mathrm{f}_{\mathrm{u}}}
\end{aligned}
$$

$\frac{f_{0.2}}{f_{u}}=\left\{\begin{array}{c}0.20+185 \frac{f_{0.2}}{E} ; \text { for austenitic, duplex and lean duplex } \\ 0.46+145 \frac{f_{0.2}}{E} ; \text { for ferritic grades }\end{array}\right.$

$\varepsilon_{\mathrm{u}}=\left\{\begin{array}{c}1-\frac{\mathrm{f}_{0.2}}{\mathrm{f}_{\mathrm{u}}} ; \text { for austenitic, duplex and lean duplex } \\ 0.6\left(1-\frac{\mathrm{f}_{0.2}}{\mathrm{f}_{\mathrm{u}}}\right) ; \text { for ferritic grades }\end{array}\right.$

Hradil et al. [34] generalized the multistage material modelling concept, with which a stress-strain curve can be split into a number of stages, depending on how much accuracy is required over the full range. Real et al. [35] performed a comparative study of material models against available stress-strain data. It was concluded that two-stage models, covering strains up to $f_{u}$, are the best balance between precision 
and practicality. However, it should be noted that stainless steel shows a non-symmetric behaviour for tensile and compression $[36,37,38]$ and therefor the use of a compressive stress-strain model, such as the material model used in [18], might be more appropriate. On the other hand, the adoption of a compressive material behaviour would incapacitate the use of nominal material parameters and stainless steel grades for which no compressive material behaviour is available.

\subsubsection{Geometric imperfections}

The common method of introducing geometric imperfections into numerical models is to perform a linear buckling analysis prior to the non-linear analysis [23, 24], from which the imperfection shapes relevant to the studied failure mode will be extracted and used to model the initial imperfections. This approach was employed in all the aforementioned research papers $[6,15,16,28,18,21]$.

The maximum allowed out-of-straightness for a column is $L / 750$ according to the fabrication tolerances set out in Annex D of EN 1090-2 (2011) [39]. EN 1993-1-5 [40] recommends using a global equivalent imperfection amplitude of $80 \%$ of the fabrication tolerances or $L / 1000$ for FE-modelling. In [41], Bjorhovde concluded that the mean initial out-of-straightness of a long column is $L / 1500$.

The fabrication tolerance for the local imperfections in welded cross-sections is $b / 100$ for flanges and $\left(h-2 t_{f}\right) / 100$ for webs according to EN 1090-2 [39], where $b$ is the width of the flange, $h$ is height of the section and $t_{\mathrm{f}}$ is the thickness of the flange. EN 1993-1-5 [40] recommends taking a local imperfection amplitude of $d / 200$ where $d$ is the unsupported width of the considered plate. Dawson and Walker [42] developed a predictive model for local imperfections in simply supported plates and hollow sections made of carbon steel. This model was then modified by Gardner et al. [23] leading to Eq. (23) in which $\omega_{0}$ is the imperfection amplitude, $f_{c r \text { min }}$ is the critical buckling stress for the most slender plate element in the section and $t$ is the plate thickness. This formula has been shown to provide accurate results for modelling of hollow [27, 24] and I-section [6] stainless steel stub columns.

$\omega_{0}=0.023\left(\frac{\mathrm{f}_{0.2}}{\mathrm{f}_{\text {cr,min }}}\right) \mathrm{t}$

\subsubsection{Residual stresses}

The models for residual stresses in carbon steel sections are well-documented [43, 44]. The ECCS [44] and the Swedish code BSK [43] propose a predictive model for residual stresses induced in carbon steel sections by conventional welding procedures. These residual stresses cause premature yielding and loss of stiffness, often resulting in a reduced loading capacity [45]. Stainless steel however, has different stress-strain and thermal properties compared to carbon steel [45]. In [46], Gardner and Cruise gathered 
the available residual stress measurement data for stainless steel sections from published research and

336 proposed predictive models, including one for welded I-sections of austenitic and austenitic-ferritic

337 grade. In [47], Yuan et al. performed an investigation into the residual stress magnitudes and

338 distributions in stainless steel built-up sections. Based on their measurements and those available in the

339 literature, a new predictive model was proposed for membrane residual stresses in built-up sections of

340 austenitic, ferritic and duplex grades. Gardner et al. [17] also carried out residual stress measurements

341 on laser-welded austenitic stainless steel I-sections. Based on the limited results available for laser-

342 welded sections, a predictive model was proposed that could safely be adopted for austenitic alloys.

343 Table 5 summarises the membrane residual stress models available in the literature for carbon and

344 stainless steel welded I-sections, where $f_{w t}$ and $f_{f t}$ are the maximum tensile residual stresses in the web

345 and the flange, respectively, $f_{w c}$ and $f_{f c}$ are the maximum compressive residual stresses in the web and

346 the flange, respectively and the $a, b, c$, and $d$ are the model parameters as shown in Figure 3. The

347 compressive residual stresses are determined assuming global equilibrium, which are provided in

348 equation form for I-sections, where $b_{f}$ and $h_{\mathrm{w}}$ are the flange width and the web height, respectively, and

349 all other parameters are as previously defined.

Table 5. Residual stress model parameters.

\begin{tabular}{|c|c|c|c|c|c|c|c|}
\hline Reference & Grade & $\mathrm{f}_{\mathrm{ft}}=\mathrm{f}_{\mathrm{wt}}$ & $\mathrm{f}_{\mathrm{fc}}=\mathrm{f}_{\mathrm{wc}}$ & $\mathrm{a}$ & $\mathrm{b}$ & $\mathrm{c}$ & d \\
\hline [44] & Carbon steel & $f_{y}$ & $0.25 f_{y}$ & $0.05 b_{f}$ & $0.15 b_{f}$ & $0.075 \mathrm{~h}_{\mathrm{w}}$ & $0.05 \mathrm{~h}_{\mathrm{w}}$ \\
\hline [43] & Carbon steel & $\mathrm{f}_{\mathrm{y}}$ & $\begin{array}{l}\text { From } \\
\text { equilibrium }\end{array}$ & $0.75 \mathrm{t}_{\mathrm{f}}$ & $1.5 \mathrm{t}_{\mathrm{f}}$ & $1.5 \mathrm{t}_{\mathrm{w}}$ & $1.5 \mathrm{t}_{\mathrm{w}}$ \\
\hline [46] & $\begin{array}{l}\text { Austenitic and } \\
\text { Duplex }\end{array}$ & $1.3 \mathrm{f}_{\mathrm{y}}$ & $\begin{array}{l}\text { From } \\
\text { equilibrium }\end{array}$ & $1.5 \mathrm{t}_{\mathrm{f}}$ & $1.5 \mathrm{t}_{\mathrm{f}}$ & $3 \mathrm{t}_{\mathrm{w}}$ & $1.5 \mathrm{t}_{\mathrm{w}}$ \\
\hline [47] & Austenitic & $0.8 \mathrm{f}_{\mathrm{y}}$ & From Eq. (24) & $0.225 b_{f}$ & $0.05 b_{f}$ & $0.025 \mathrm{~h}_{\mathrm{w}}$ & $0.225 h_{w}$ \\
\hline [47] & Ferritic and Duplex & $0.6 f_{y}$ & From Eq. (24) & $0.225 b_{f}$ & $0.05 b_{f}$ & $0.025 \mathrm{~h}_{\mathrm{w}}$ & $0.225 \mathrm{~h}_{\mathrm{w}}$ \\
\hline [17] & $\begin{array}{l}\text { Austenitic Laser- } \\
\text { welded }\end{array}$ & $0.5 \mathrm{f}_{\mathrm{y}}$ & $\begin{array}{l}\text { From } \\
\text { equilibrium }\end{array}$ & $0.1 b_{f}$ & $0.075 b_{f}$ & $0.025 \mathrm{~h}_{\mathrm{w}}$ & $0.05 \mathrm{~h}_{\mathrm{w}}$ \\
\hline
\end{tabular}




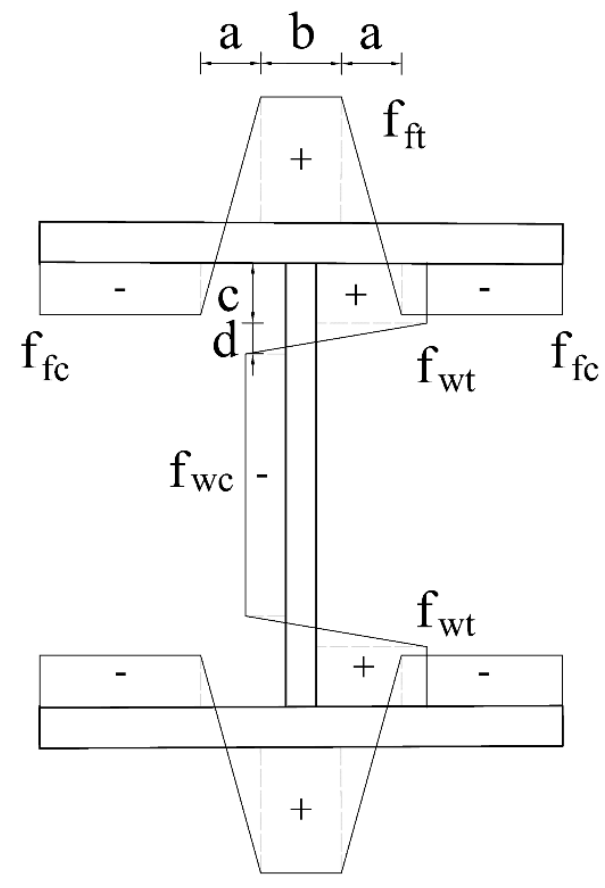

Figure 3. Residual stress model [17].

For I-sections $\left\{\begin{array}{c}f_{\mathrm{fc}}=\frac{\mathrm{a}+\mathrm{b}}{\mathrm{b}_{\mathrm{f}}-(\mathrm{a}+\mathrm{b})} \mathrm{f}_{\mathrm{ft}} \\ f_{\mathrm{wc}}=\frac{2 \mathrm{c}+\mathrm{d}}{\mathrm{h}_{\mathrm{w}}-(2 \mathrm{c}+\mathrm{d})} \mathrm{f}_{\mathrm{wt}}\end{array}\right.$

354 In built-up sections, these membrane residual stresses due to the welding process are of significant

355 magnitude. They need to be applied to the structural element separately. In the papers mentioned in

356 Table 4, residual stresses were assigned to the FEM elements by partitioning the web and flanges [6, 15,

$35728,18]$ in the models. The bending residual stresses are present in the plate material extracted from the

358 structural section, hence they are incorporated in the material behaviour derived from tensile coupon

359 tests. Therefore they do not have to be incorporated in FE-models [46].

\subsection{Validation of numerical model}

361 Finite element models were developed and validated herein for the purpose of conducting a parametric 362 study on welded stainless steel I-section columns. Abaqus was used and the modelling assumptions similar to those adopted by other numerical investigations as described in Section 4.1 were adopted. An overview of the key features of the models is presented hereafter. The column tests reported in Ahmed et al. [12] were used to validate the FE models. The measured geometric properties were used. Boundary conditions were applied to the centroid of the end plates (which coincides with the centroid of the column). All translational and rotational degrees of freedom at the column ends, except the rotation about the minor axis, were restrained. The chosen element type is S4R with a mesh size equal to $4 \mathrm{~mm}$. 
Tensile coupon tests were performed in [12]. Rasmussen's [32] material model has been fitted to these curves by the authors and the resulting parameters are given in [12].

371 In order to model the residual stresses from welding, partitions were made in the web and flanges and 372 predefined fields with longitudinal stresses were assigned to them. Models with, three cases of residual stresses were compared including (1) the residual stress model for carbon steel available in ECCS [44], (2) the residual stress model for stainless steel proposed by Yuan et al. [47] as presented in Section 4.1.4 and (3) no residual stresses. The comparison results are shown in Figure 4 for one of the tested columns. It was concluded that (1) the residual stresses present have a significant influence on the load-versuslateral displacement behaviour of the column and result in the response to deviate from linearity at lower stresses and reach lower ultimate loads and (2) both ECCS model [44] and the Yuan et al. model [47] give similar predictions of the column behaviour.

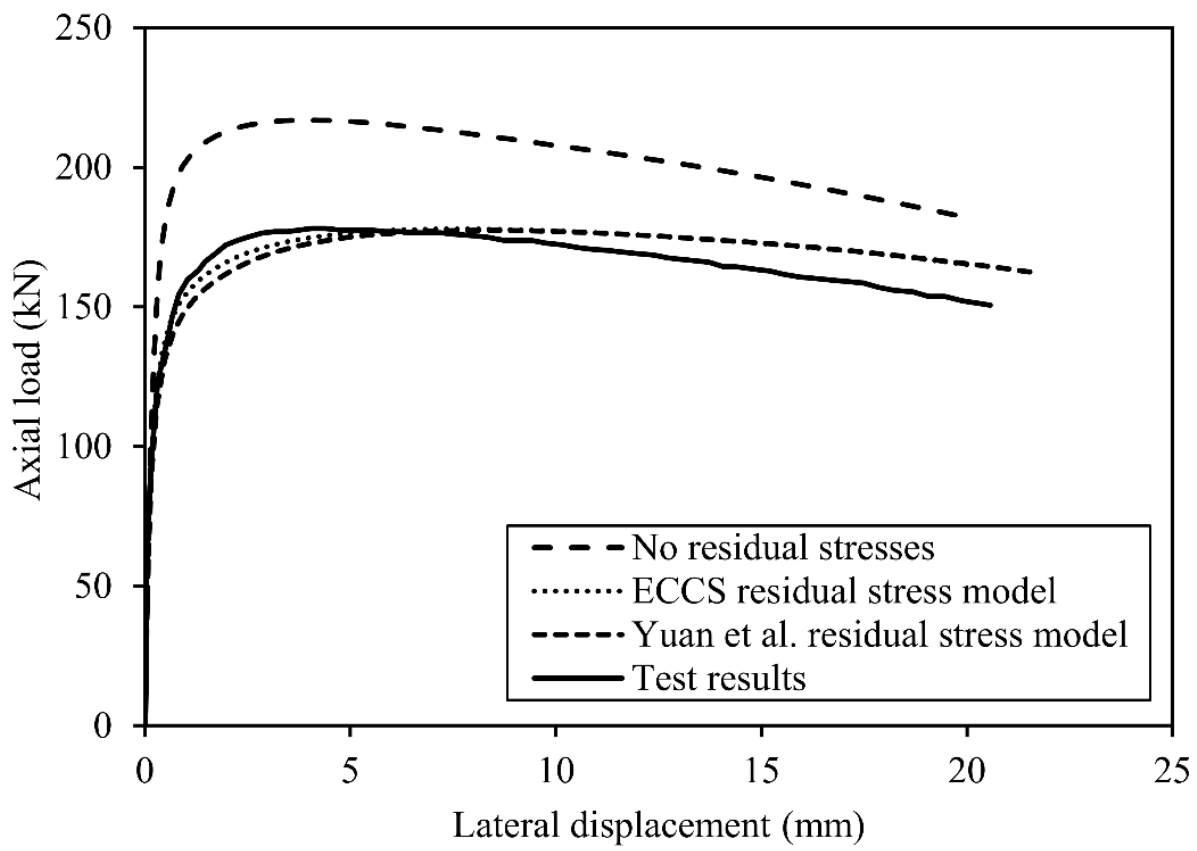

Lateral displacement $(\mathrm{mm})$

Figure 4. Axial load - lateral displacement at half-length for different residual stress models $(80 \times 80 \times 4 \times 5-1200)$.

Three geometric imperfection amplitudes have been measured in [12]. They were introduced in the form of lowest local buckling mode shape and minor axis or major axis flexural buckling mode shapes (depending on which failure mode is considered) with their corresponding measured amplitudes, as described in Section 4.1.3. Figure 5 shows the influence of global imperfection, using the residual stress model of Yuan et al. [47] and a measured local imperfection.

For a numerical parametric study, EN 1993-1-5 [40] recommends that the imperfection amplitude is set to $80 \%$ of the fabrication tolerances set-out in EN 1090-2 [39]. The 2008 version of EN 1090-2 [39] imposes a tolerance of $L / 750$ for the straightness of a column, where $\mathrm{L}$ is the column length, leading to an equivalent geometric imperfection amplitude of approximately $L / 1000$. However, in [41], Bjorhovde concluded that the mean initial out-of-straightness of a long column is $L / 1470$. Since this study was 
published in 1972, fabrication methods have become more advanced, leading to even smaller imperfections. This statement is confirmed by the 16 columns of Ahmed et al. [12], which had an average measured global imperfection of L/2150. Furthermore, the EN 1090-2 [39] code has been revamped recently (2018) and the fabrication tolerance for the straightness of a column had been changed to $L / 1000$, leading to an equivalent geometric imperfection of $L / 1250$. The latter arguments confirm that $L / 1000$ is a conservative value for use in a parametric study. However, to allow comparisons with previous parametric studies, it was nevertheless chosen to use a conservative geometric global imperfection amplitude of $L / 1000$ in the parametric study.

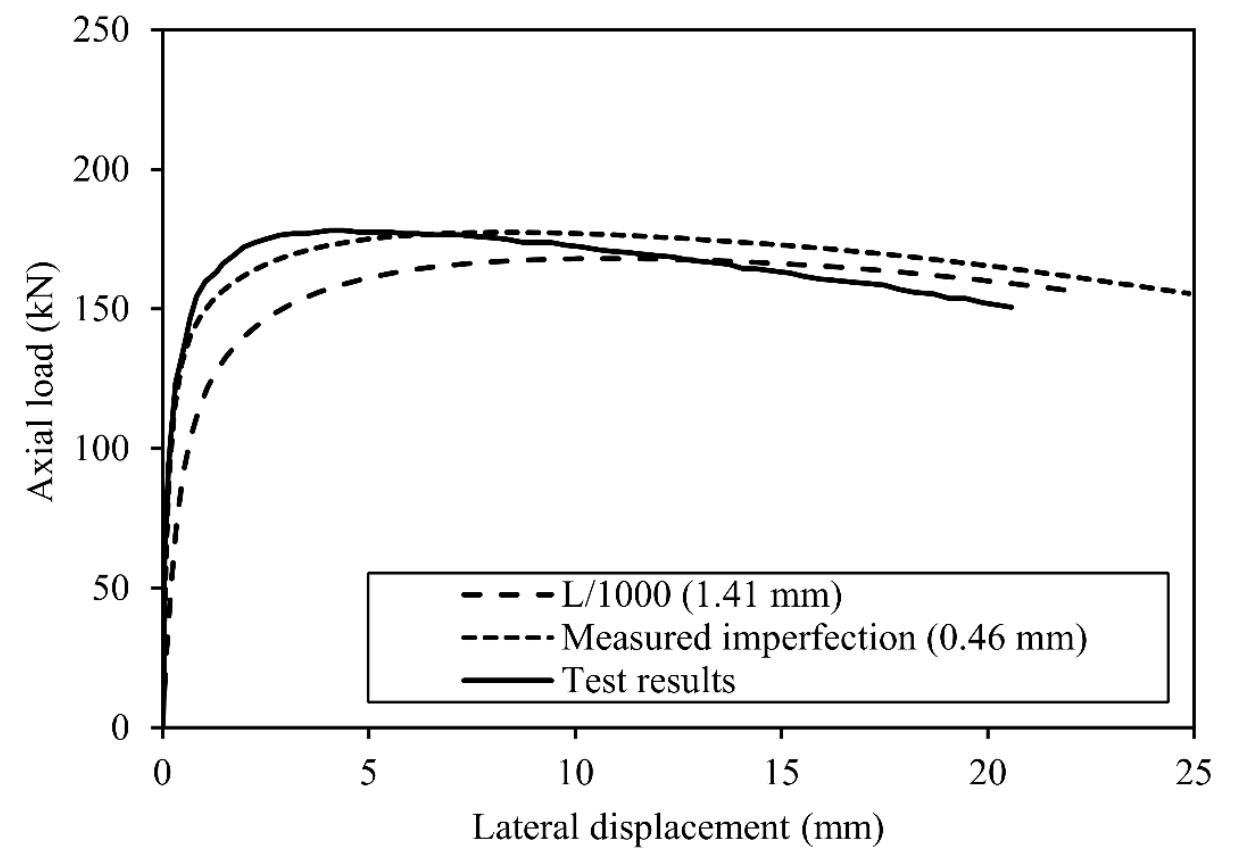

400

401

Figure 5. Axial load - lateral displacement at half-length for different global imperfection amplitudes $(80 \times 80 \times 4 \times 5-1200)$.

Figure 6 shows the influence of the local imperfection, using the residual stress model of Yuan et al. [47] and the measured global imperfection. The influence of the local imperfection is insignificant for both minor axis and major axis buckling. Both the $d / 200$ recommendation and the recommendation of Gardner et al. [23] (as described in Section 4.1.3) generate accurate results. However, according to the local imperfection measurements of Ahmed et al. [12] and Yuan et al. [5], the $d / 200$ recommendation gives better amplitude predictions than the Dawson and Walker model by Gardner et al. [23], which was developed for hot-rolled and cold-formed stainless steel angles and hollow sections. The local imperfection amplitude was therefore set to $d / 200$ in the parametric study 


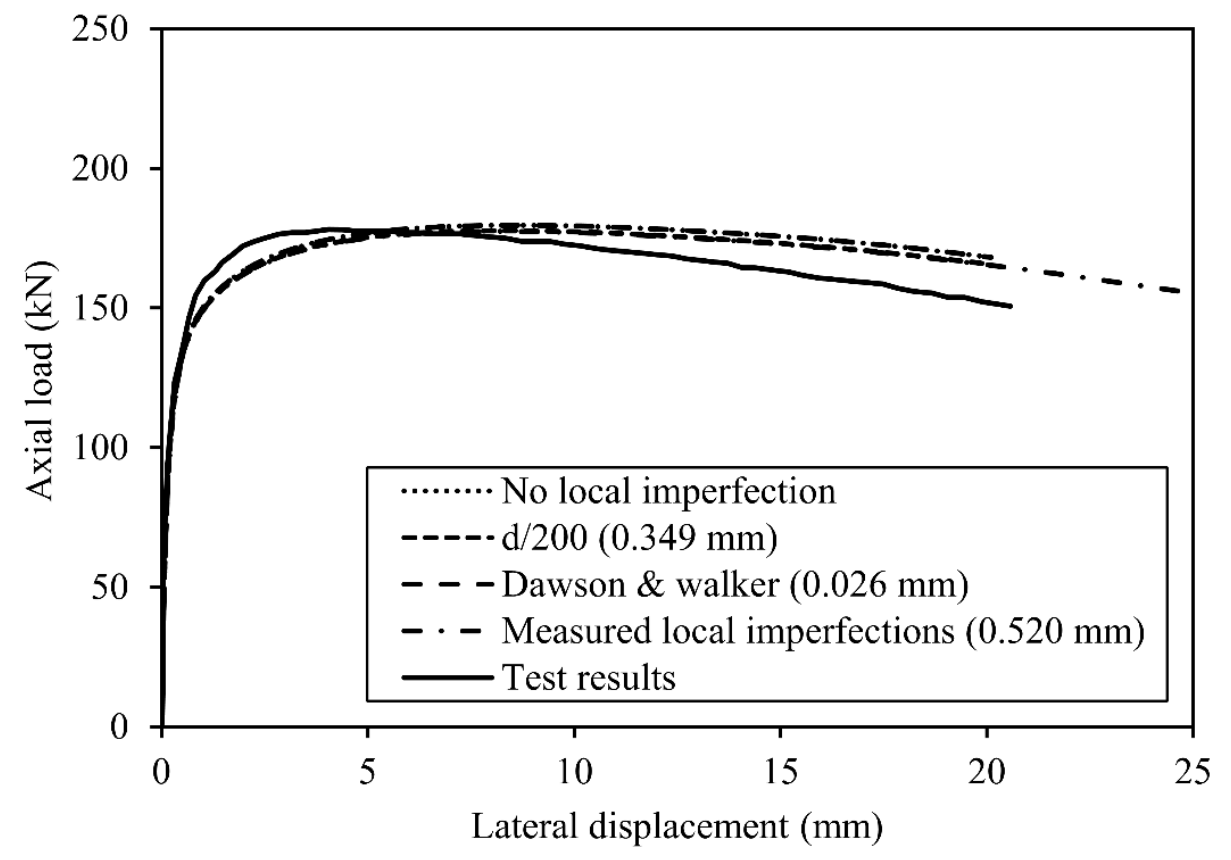

Figure 6. Axial load - lateral displacement at half-length for different local imperfection amplitudes $(80 \times 80 \times 4 \times 5$

$-1200)$.

\section{$414 \quad 4.3$ Comparison against Ahmed et al.}

415 The described modelling technique was used to model all 16 tests performed by Ahmed et al. in [12].

416 Three load-versus-displacement curves comparing the FE models with the corresponding test results are

417 shown in Figure 7. Table 6 gives a comparison of the ultimate loads from test $N_{\text {test }}$ and FE $N_{\text {FE. }}$. Beyond 418 the ultimate load, the tests generally show a sharper decline in load than the FE models. The modelling 419 technique is however deemed satisfactory for parametric studies of welded stainless steel I-section 420 columns as the ultimate strength prediction is very accurate with an mean FE-to-test strength ratio of $421 \quad 0.99$ and a COV of 0.04. 


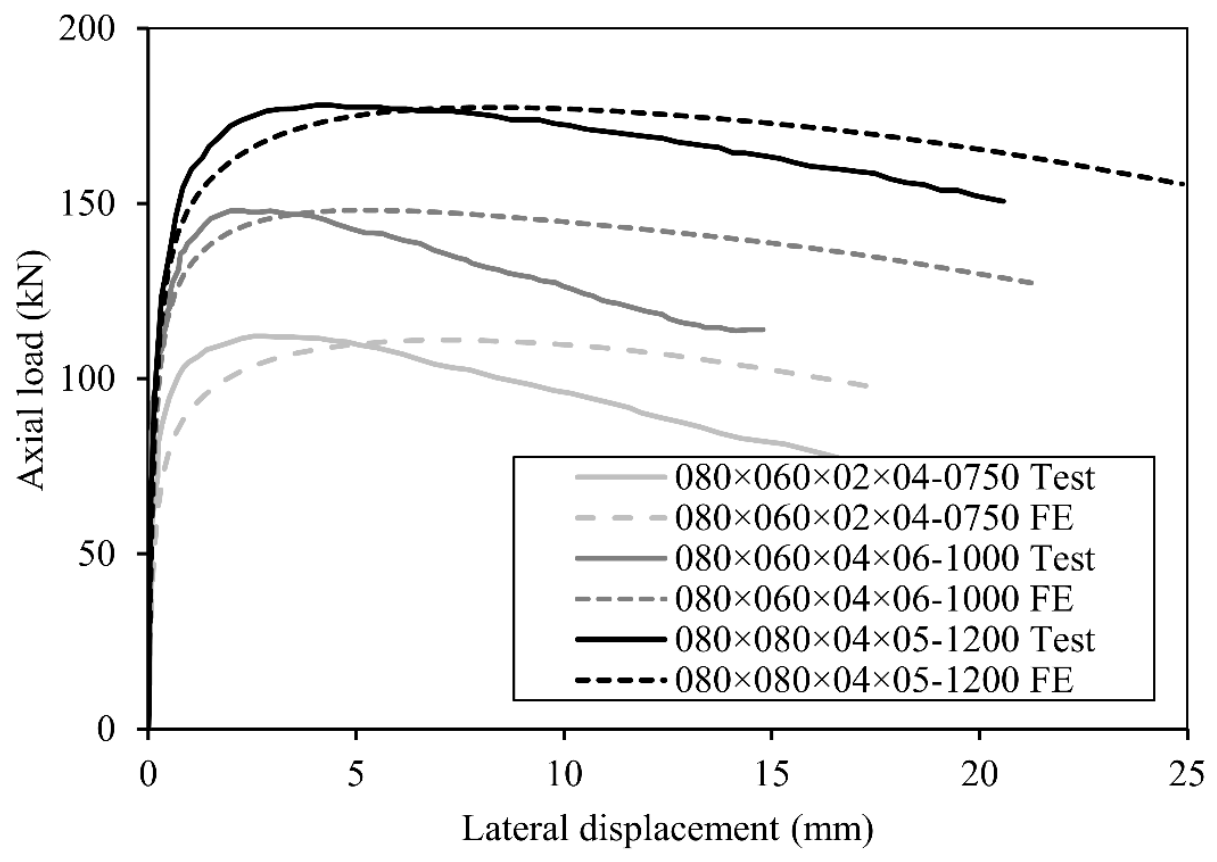

Figure 7. Comparison of FE simulation and test result [12] for three columns.

Table 6. Comparison of ultimate loads from FE and test [12].

\begin{tabular}{llll}
\hline & $\mathrm{N}_{\mathrm{FE}}[\mathrm{kN}]$ & $\mathrm{N}_{\text {Test }}[\mathrm{kN}]$ & $\mathrm{N}_{\mathrm{FE}} / \mathrm{N}_{\text {Test }}$ \\
\hline $80 \times 60 \times 2 \times 4-750$ & 111.0 & 112.9 & 0.98 \\
$80 \times 60 \times 2 \times 4-1000$ & 84.7 & 92.6 & 0.92 \\
$80 \times 60 \times 2 \times 4-1500$ & 53.8 & 56.3 & 0.96 \\
$80 \times 60 \times 4 \times 6-750$ & 181.9 & 189.8 & 0.96 \\
$80 \times 60 \times 4 \times 6-1000$ & 148.1 & 149.4 & 0.99 \\
$80 \times 60 \times 4 \times 6-1200$ & 129.2 & 123.8 & 1.04 \\
$80 \times 80 \times 4 \times 5-500$ & 273.2 & 288.0 & 0.95 \\
$80 \times 80 \times 4 \times 5-900$ & 214.3 & 216.0 & 0.99 \\
$80 \times 80 \times 4 \times 5-1200$ & 177.4 & 178.3 & 0.99 \\
$80 \times 60 \times 4 \times 6-450$ & 254.7 & 260.1 & 0.98 \\
$80 \times 60 \times 4 \times 6-900$ & 165.9 & 171.9 & 0.97 \\
$80 \times 60 \times 4 \times 6-1200$ & 131.5 & 127.0 & 1.04 \\
$120 \times 60 \times 3 \times 5-720$ & 162.9 & 177.0 & 0.92 \\
$120 \times 60 \times 3 \times 05-1200$ & 107.4 & 104.6 & 1.03 \\
$120 \times 60 \times 2 \times 4-500$ & 153.4 & 150.9 & 1.02 \\
$120 \times 60 \times 2 \times 4-1000$ & 91.0 & 93.7 & 0.97 \\
\hline
\end{tabular}




\begin{tabular}{|c|c|c|c|}
\hline & $\mathrm{N}_{\mathrm{FE}}[\mathrm{kN}]$ & $\mathrm{N}_{\text {Test }}[\mathrm{kN}]$ & $\mathrm{N}_{\mathrm{FE}} / \mathrm{N}_{\text {Test }}$ \\
\hline Mean & & & 0.98 \\
\hline $\mathrm{COV}$ & & & 0.04 \\
\hline
\end{tabular}

\section{Parametric study}

\subsection{Introduction}

The previously described modelling technique was used to perform a parametric study to assess the buckling behaviour of welded I-section stainless steel columns over the whole slenderness range. Four different grades of stainless steel were studied: two duplex (EN 1.4162 and EN 1.4462), one austenitic (EN 1.4301) and one ferritic (EN 1.4512). For each grade, except the duplex EN 1.4162, reference laboratory tests for minor axis buckling were found in the literature. No reference tests for major axis buckling on columns made of ferritic EN 1.4512 and duplex EN 1.4162 grades were found in the literature. All the aforementioned results (experimental and numerical results from the literature combined with this parametric study) are then used to assess the performance of the European buckling curves for minor and major axis buckling of I-section welded columns. The predictions of the flexural buckling CSM approach are also compared to the numerical results. In all comparisons, the partial safety factors have been set to unity.

The following modelling assumptions were adopted in the parametric study:

- $\quad$ All modelled columns had welded I-cross-sections as shown in Figure 8.

- A mesh size of minimum sixteen elements along the plate width in a cross-section was employed. Specifically, the element size for the flanges was $b / 16$ and the element size for the web was taken as the minimum of $\left(h-t_{f}\right) / 16$ and $b / 8$. The only exception to these element sizes were the partitions needed to input the residual stress distribution.

- The compound Ramberg-Osgood material model as modified by Rasmussen [32] with the proposal from Arrayago et al. [33] was used. The nominal material properties for hot-rolled plates as provided in [4] were used. For the ferritic grade EN 1.4512, the properties from EN 10088-2 (2014) [48] were used. These are reported in Table 7.

- The residual stress model proposed by Yuan et al. [47] was adopted.

- The global and local imperfection amplitudes were set to $L / 1000$ and $d / 200$, respectively. 
Table 7. Material parameters used in parametric study.

\begin{tabular}{llllllll}
\hline Family & Grade & $\begin{array}{l}\mathrm{E} \\
{\left[\mathrm{N} / \mathrm{mm}^{2}\right]}\end{array}$ & $\begin{array}{l}\mathrm{f}_{\mathrm{y}} \\
{\left[\mathrm{N} / \mathrm{mm}^{2}\right]}\end{array}$ & $\begin{array}{l}\mathrm{f}_{\mathrm{u}} \\
{\left[\mathrm{N} / \mathrm{mm}^{2}\right]}\end{array}$ & $\begin{array}{l}\mathrm{n} \\
{[-]}\end{array}$ & $\begin{array}{l}\varepsilon_{\mathrm{u}} \\
{[-]}\end{array}$ & $\begin{array}{l}\mathrm{m} \\
{[-]}\end{array}$ \\
\hline Austenitic & EN 1.4301 & 200000 & 210 & 520 & 7 & 0.596 & 2.131 \\
Ferritic & EN 1.4512 & 200000 & 210 & 380 & 14 & 0.268 & 2.547 \\
Duplex & EN 1.4162 & 200000 & 480 & 680 & 8 & 0.294 & 2.976 \\
Duplex & EN 1.4462 & 200000 & 460 & 700 & 8 & 0.281 & 3.013 \\
\hline
\end{tabular}

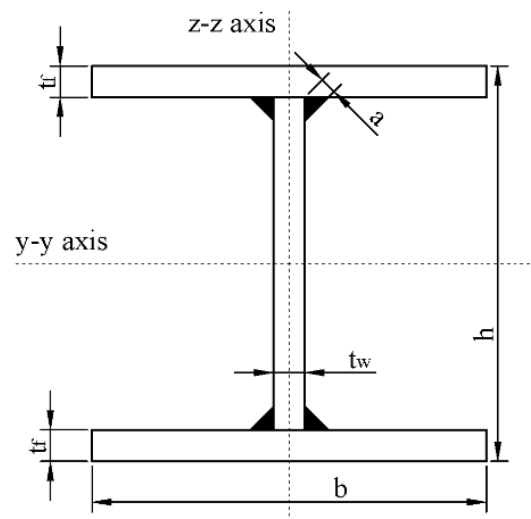

Height: $h$

Width of flange: $b$

Thickness of flange $1: t_{f}$

Thickness of web: $t_{w}$

Cross-sectional area: A

Weld throat thickness: a

Strong-axis: $y-y$

Weak-axis: z-z

Moment of inertia about $y-y$ axis: $I_{y}$

Moment of inertia about $\mathrm{z}-\mathrm{z}$ axis: $\mathrm{I}_{\mathrm{z}}$

Figure 8. Definition of symbols for welded I-section.

\subsection{Minor axis buckling}

\subsubsection{Modelling assumptions for minor axis buckling}

456 For minor axis buckling, the boundary conditions are pinned-pinned about the minor axis and fixed-

457 fixed about the major axis. Ten different lengths and eleven different cross-sections were modelled 458 allowing a wide range of column slendernesses $(0.24<\bar{\lambda}<2.44)$ to be studies. All modelled 459 combinations are shown in Table 8, where the lengths are in $\mathrm{mm}$ and the cross-section name is given as $460 \quad$ ' $h \times b \times t_{w} \times t_{f}$ ' (in $\mathrm{mm}$ ) and the symbols are as defined in Figure 8.

Table 8. Geometric dimensions of tests performed in minor axis parametric study [mm].

\begin{tabular}{lccll}
\hline $\begin{array}{l}\text { Minor axis (440 FE models) } \\
\text { Grades (4) }\end{array}$ & Lengths (10) & & Cross-sections (11) & \\
\hline EN 1.4301 & 0600 & 2600 & $100 \times 100 \times 04 \times 04$ & $175 \times 100 \times 05 \times 08$ \\
& 1000 & 3000 & $100 \times 100 \times 04 \times 06$ & $200 \times 100 \times 05 \times 08$ \\
& 1400 & 3400 & $125 \times 100 \times 04 \times 05$ & $200 \times 100 \times 10 \times 10$ \\
& 1800 & 3800 & $150 \times 100 \times 04 \times 05$ & $225 \times 100 \times 06 \times 10$ \\
& 2200 & 4200 & $150 \times 100 \times 06 \times 06$ & $250 \times 100 \times 08 \times 12$ \\
EN 1.4512 & 0600 & 2600 & $175 \times 100 \times 05 \times 06$ & \\
& 1000 & 3000 & $100 \times 100 \times 04 \times 04$ & $175 \times 100 \times 05 \times 08$ \\
& & & & $200 \times 100 \times 06 \times 08$
\end{tabular}




\begin{tabular}{lccll}
\hline $\begin{array}{l}\text { Minor axis (440 FE models) } \\
\text { Grades (4) }\end{array}$ & Lengths (10) & & Cross-sections (11) & \\
\hline & 1400 & 3400 & $125 \times 100 \times 04 \times 06$ & $200 \times 100 \times 10 \times 10$ \\
& 1800 & 3800 & $150 \times 100 \times 04 \times 06$ & $225 \times 100 \times 06 \times 10$ \\
& 2200 & 4200 & $150 \times 100 \times 06 \times 06$ & $250 \times 100 \times 08 \times 10$ \\
EN 1.4462 & & & $175 \times 100 \times 05 \times 06$ & \\
& 0400 & 1900 & $100 \times 100 \times 04 \times 06$ & $175 \times 100 \times 12 \times 12$ \\
& 0700 & 2200 & $100 \times 100 \times 08 \times 08$ & $200 \times 100 \times 08 \times 10$ \\
& 1000 & 2500 & $125 \times 100 \times 05 \times 06$ & $200 \times 100 \times 08 \times 12$ \\
EN 1.4162 & 1300 & 2800 & $150 \times 100 \times 06 \times 08$ & $225 \times 100 \times 08 \times 12$ \\
& 1600 & 3100 & $150 \times 100 \times 06 \times 10$ & $250 \times 100 \times 10 \times 12$ \\
& 0400 & 1900 & $175 \times 100 \times 08 \times 10$ & \\
& 0700 & 2200 & $100 \times 100 \times 04 \times 06$ & $175 \times 100 \times 10 \times 10$ \\
& 1000 & 2500 & $125 \times 100 \times 05 \times 08$ & $200 \times 100 \times 08 \times 08$ \\
& 1300 & 2800 & $150 \times 100 \times 06 \times 08$ & $225 \times 100 \times 10 \times 10$ \\
& 1600 & 3100 & $150 \times 100 \times 06 \times 10$ & $250 \times 100 \times 10 \times 10$ \\
& & & $175 \times 100 \times 08 \times 10$ & \\
\hline
\end{tabular}

\subsubsection{Minor axis results}

464 The generated numerical data combined with the gathered test data for minor axis flexural buckling of 465 welded I-section columns were compared with the current EN 1993-1-4 [3] ( $\alpha=0.76)$ and the CSM1 466 buckling curves, as shown in Figure 9 and Figure 10, respectively. The EN 1993-1-4 [3] buckling curve 467 for major axis buckling with $\alpha=0.49$ is also depicted for comparison purposes. The mean and COV of 468 the Eurocode-to-FE predictions using the current minor axis buckling curve (i.e. with $\alpha=0.76$ ) can be 469 found in Table 9. The result of the comparisons against the CSM predictions, including the two versions 470 as listed in Section 2.2.2, are also provided in Table 9. The CSM design predictions are based on a cross471 sectional elastic buckling stress calculated using the CUFSM [49]. Overall, the current Eurocode minor 472 buckling curve $(\alpha=0.76)$ provides conservative results for the duplex and ferritic columns. The CSM 473 enables to take the benefits of strain hardening into account, reducing the level of conservativeness of 474 the code, especially in the low slenderness range. 


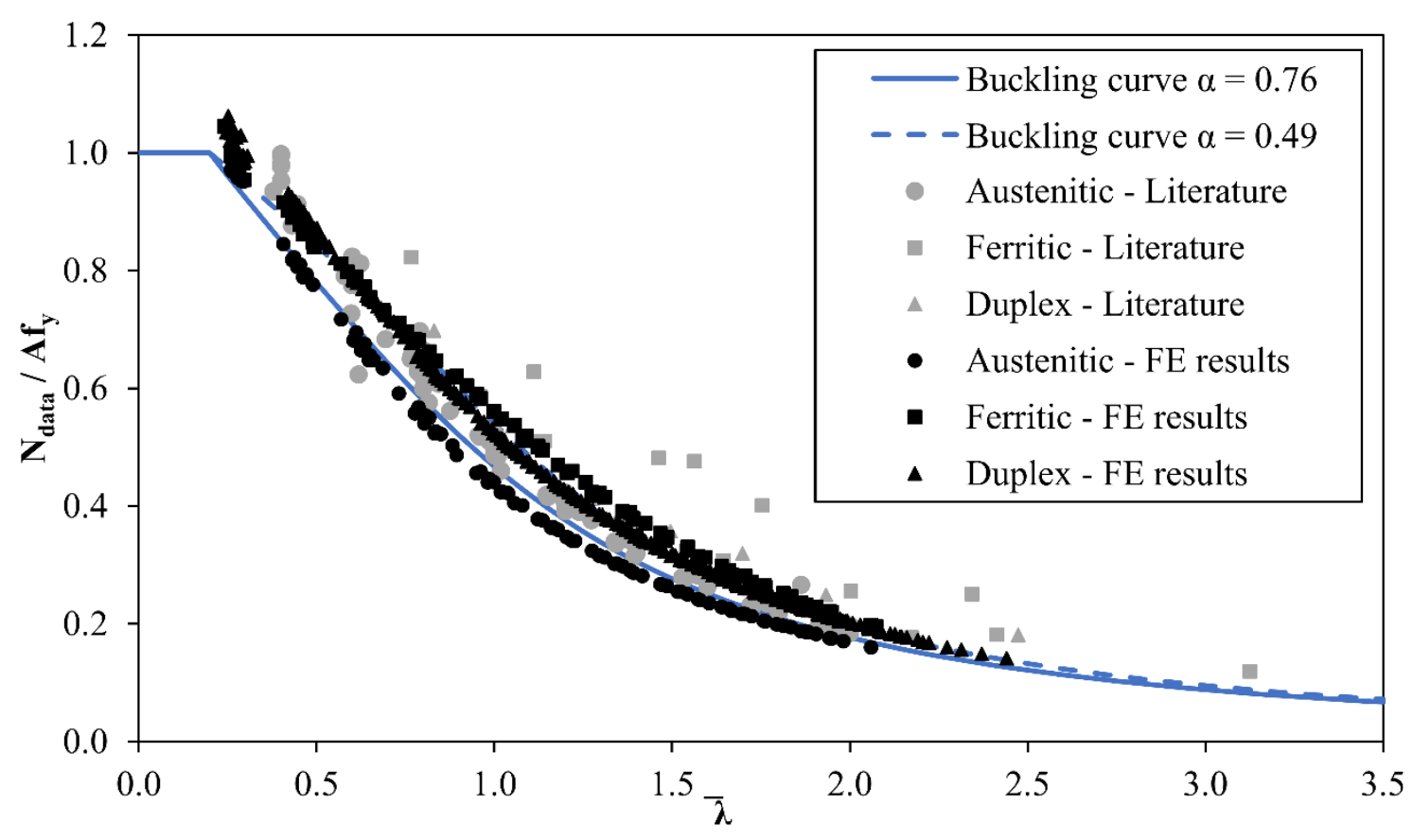

475

476

Figure 9. Comparison between the test/FE data and the Eurocode curve for minor axis flexural buckling.

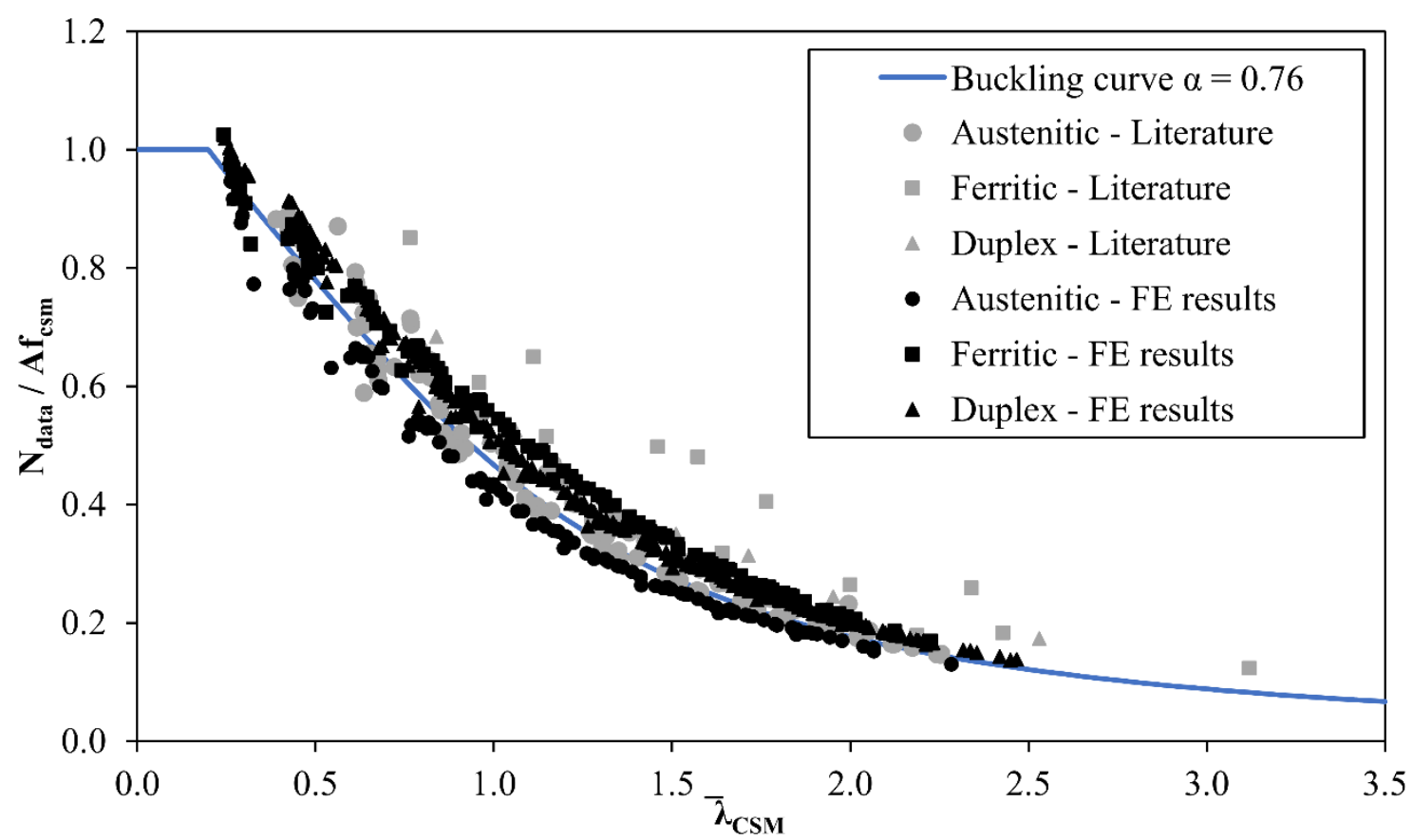

Figure 10. Comparison between the test/FE data and the CSM1 curve for minor axis flexural buckling.

Table 9. Results from minor axis flexural buckling data.

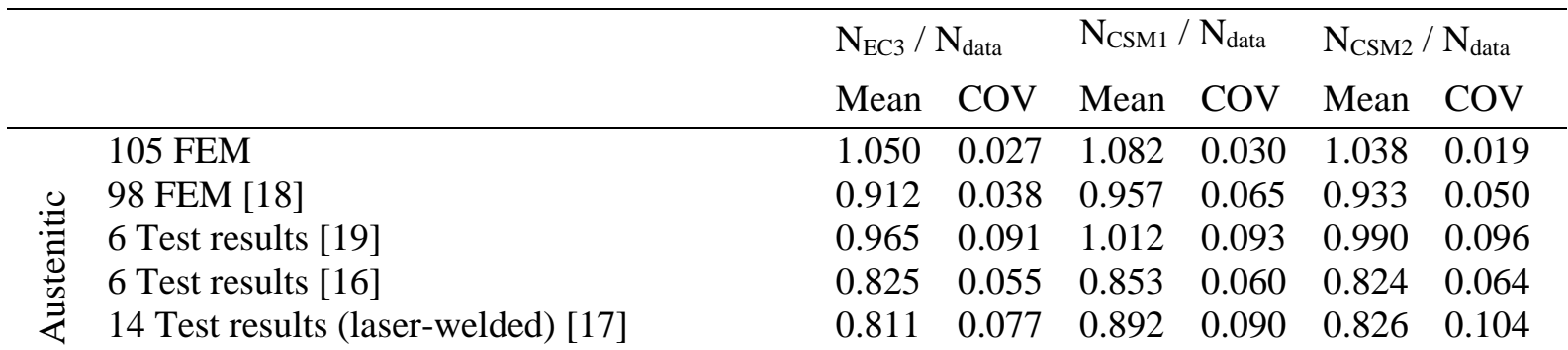




\begin{tabular}{|c|c|c|c|c|c|c|c|}
\hline & & \multicolumn{2}{|c|}{$\mathrm{N}_{\mathrm{EC} 3} / \mathrm{N}_{\text {data }}$} & \multicolumn{2}{|c|}{$\mathrm{N}_{\text {CSM1 }} / \mathrm{N}_{\text {data }}$} & \multicolumn{2}{|c|}{$\mathrm{N}_{\mathrm{CSM} 2} / \mathrm{N}_{\text {data }}$} \\
\hline & & Mean & $\mathrm{COV}$ & Mean & $\mathrm{COV}$ & Mean & $\mathrm{COV}$ \\
\hline & 16 Test results [12] & 0.926 & 0.022 & 0.958 & 0.051 & 0.933 & 0.043 \\
\hline & All 245 FEM and test results & 0.965 & 0.089 & 1.006 & 0.087 & 0.971 & 0.081 \\
\hline \multirow{3}{*}{ : } & 108 FEM & 0.857 & 0.057 & 0.869 & 0.065 & 0.861 & 0.067 \\
\hline & 13 Test results [13] & 0.672 & 0.160 & 0.672 & 0.160 & 0.670 & 0.160 \\
\hline & All 121 FEM and test results & 0.837 & 0.097 & 0.848 & 0.104 & 0.840 & 0.104 \\
\hline \multirow{3}{*}{$\begin{array}{l}\frac{\sqrt[x]{\tilde{a}}}{\hat{a}} \\
\hat{\Xi}\end{array}$} & 216 FEM results & 0.886 & 0.018 & 0.910 & 0.037 & 0.928 & 0.032 \\
\hline & 6 Test results [16] & 0.759 & 0.071 & 0.764 & 0.073 & 0.782 & 0.076 \\
\hline & All 222 FEM and test results & 0.883 & 0.031 & 0.906 & 0.046 & 0.924 & 0.042 \\
\hline \multicolumn{2}{|c|}{ ALL DATA (588 results) } & 0.908 & 0.095 & 0.936 & 0.103 & 0.926 & 0.091 \\
\hline
\end{tabular}

\subsection{Major axis buckling}

\subsubsection{Modelling assumptions for major axis buckling}

For major axis buckling, the boundary conditions are pinned-pinned about the major axis and fixedfixed about the minor axis. Additionally, the lateral displacement in the direction of the minor axis is restrained at six nodes, three on the top flange and three on the bottom flange. The nodes are located at a quarter, halfway and at three quarters of the column height.

The studied geometries are provided in Table 10. Thirteen lengths were considered for nine different cross-sections, covering a wide range of column slendernesses $(0.23<\bar{\lambda}<2.09)$. The same four stainless steel grades were modelled, despite the fact that no major axis column test data were available

$490 \quad$ in the literature for any ferritic grade or duplex grade EN 1.4162.

Table 10. Geometric dimensions of tests performed in major axis parametric study.

\begin{tabular}{|c|c|c|c|c|}
\hline \multicolumn{5}{|c|}{ Major axis (468 FE models) } \\
\hline \multirow{2}{*}{$\frac{\text { Grades (4) }}{\text { EN } 1.4301}$} & \multicolumn{2}{|c|}{ Lengths (13) } & \multicolumn{2}{|l|}{ Cross-sections (9) } \\
\hline & 1500 & 5350 & $100 \times 100 \times 03 \times 04$ & $140 \times 100 \times 05 \times 08$ \\
\hline & 2050 & 5900 & $100 \times 100 \times 04 \times 06$ & $140 \times 100 \times 08 \times 08$ \\
\hline & 2600 & 6450 & $120 \times 100 \times 03 \times 05$ & $170 \times 100 \times 06 \times 06$ \\
\hline & 3150 & 7000 & $120 \times 100 \times 04 \times 06$ & $200 \times 100 \times 05 \times 10$ \\
\hline & 3700 & 7550 & $120 \times 100 \times 08 \times 08$ & \\
\hline & 4250 & 8100 & & \\
\hline & 4800 & & & \\
\hline \multirow[t]{7}{*}{ EN 1.4512} & 1500 & 5350 & $100 \times 100 \times 03 \times 04$ & $140 \times 100 \times 05 \times 08$ \\
\hline & 2050 & 5900 & $100 \times 100 \times 04 \times 06$ & $140 \times 100 \times 08 \times 08$ \\
\hline & 2600 & 6450 & $120 \times 100 \times 04 \times 04$ & $170 \times 100 \times 06 \times 06$ \\
\hline & 3150 & 7000 & $120 \times 100 \times 04 \times 06$ & $200 \times 100 \times 05 \times 10$ \\
\hline & 3700 & 7550 & $120 \times 100 \times 08 \times 08$ & \\
\hline & 4250 & 8100 & & \\
\hline & 4800 & & & \\
\hline
\end{tabular}




\begin{tabular}{lllll} 
EN 1.4462 & 900 & 3700 & $100 \times 100 \times 04 \times 06$ & $140 \times 100 \times 06 \times 10$ \\
& 1300 & 4100 & $100 \times 100 \times 05 \times 08$ & $140 \times 100 \times 10 \times 10$ \\
& 1700 & 4500 & $120 \times 100 \times 05 \times 06$ & $170 \times 100 \times 08 \times 08$ \\
& 2100 & 4900 & $120 \times 100 \times 06 \times 08$ & $200 \times 100 \times 12 \times 08$ \\
& 2500 & 5300 & $120 \times 100 \times 08 \times 08$ & \\
EN 1.4162 & 2900 & 5700 & & \\
& 3300 & & & $140 \times 100 \times 06 \times 10$ \\
& 900 & 3700 & $100 \times 100 \times 04 \times 06$ & $140 \times 100 \times 10 \times 10$ \\
& 1300 & 4100 & $100 \times 100 \times 05 \times 08$ & \\
& 1700 & 4500 & $120 \times 100 \times 05 \times 06$ & $170 \times 100 \times 08 \times 08$ \\
& 2100 & 4900 & $120 \times 100 \times 06 \times 08$ & $200 \times 100 \times 10 \times 10$ \\
& 2500 & 5300 & $120 \times 100 \times 08 \times 08$ & \\
& 2900 & 5700 & & \\
& 3300 & & & \\
\hline
\end{tabular}

\subsubsection{Major axis results}

494 The generated numerical data combined with the gathered test and numerical data for major-axis flexural 495 buckling of welded I-section columns were compared with the current EN 1993-1-4 [3] ( $\alpha=0.49)$ and 496 the CSM1 buckling curves, as shown in Figure 11 and Figure 12, respectively. The EN 1993-1-4 [3] 497 buckling curve for minor-axis buckling with $\alpha=0.76$ is also depicted for comparison purposes. The 498 numerical comparisons are provided in Table 11.

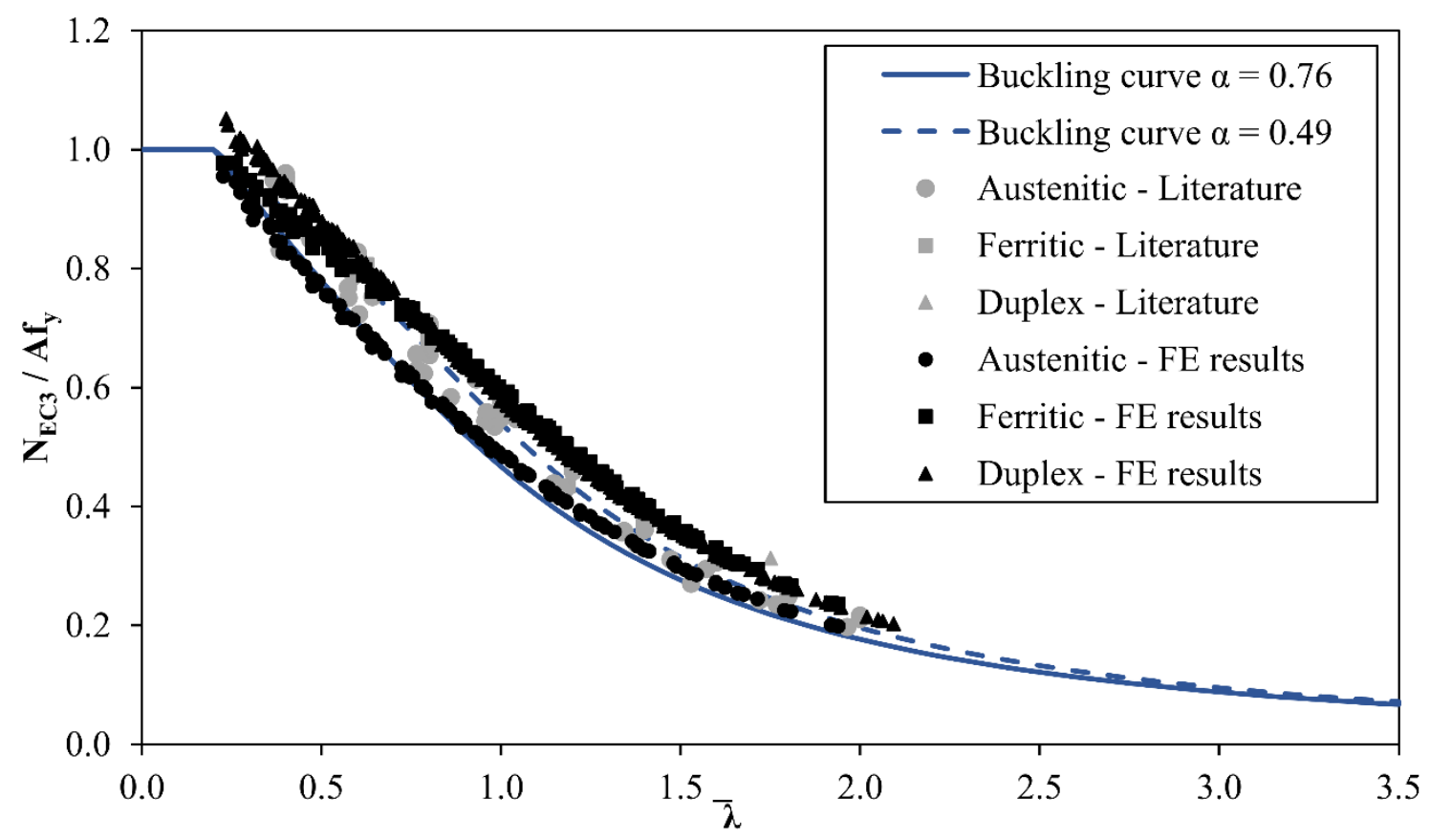

Figure 11. Comparison between the test/FE data and the Eurocode curve for major axis flexural buckling. 


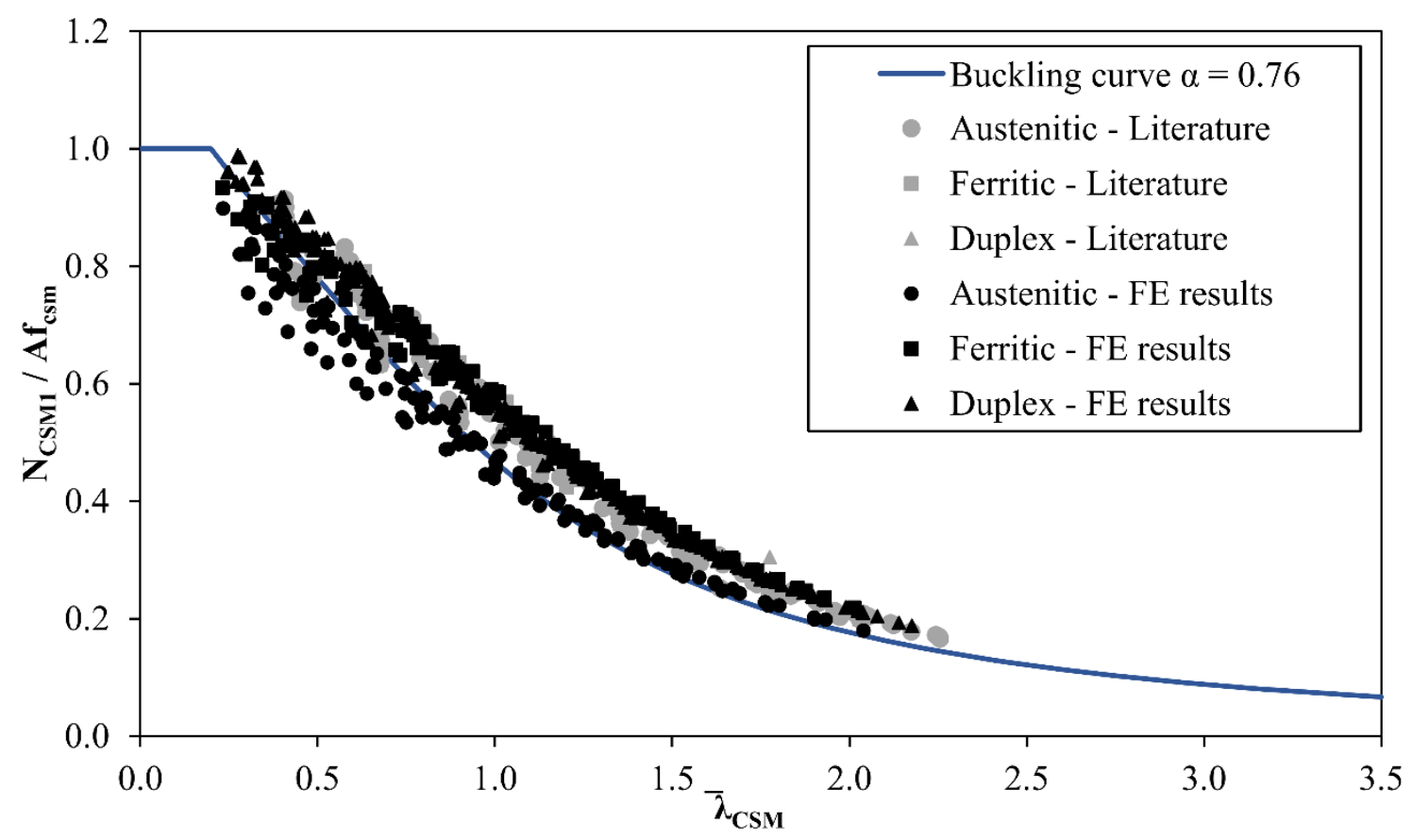

Figure 12. Comparison between the test/FE data and the CSM1 curve for major axis flexural buckling.

Table 11. Results from major axis flexural buckling data.

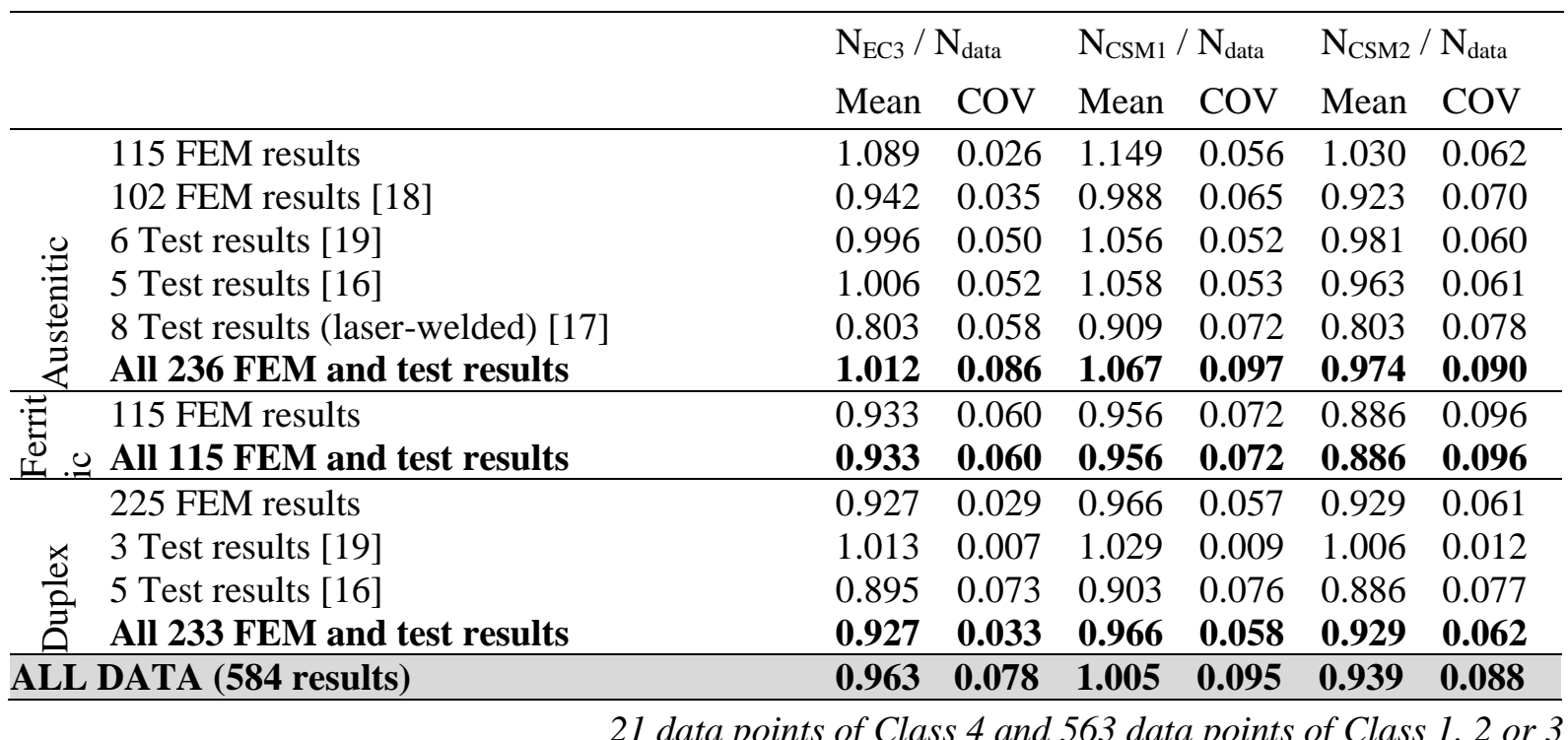

\section{Analysis of results and reliability assessment}

In the present study, the results show that the behaviour of duplex stainless steel is similar to that of ferritic stainless steel and that no distinction should be made between these families, as it is also mentioned in [6]. Overall, for those families and both buckling axes, the results for the current European buckling curves were found to be quite conservative. Some improvements can be achieved by changing the imperfection factor to 0.49 for minor axis buckling and maybe 0.34 for major axis buckling, for ferritic and duplex stainless steel, as will be shown in the next paragraphs. 


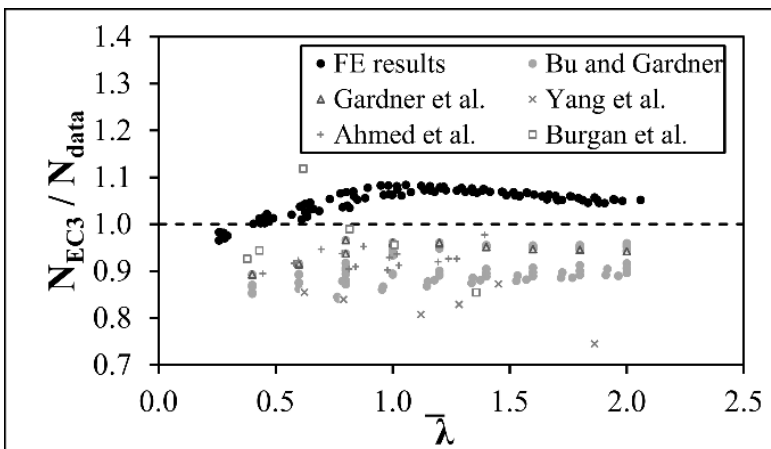

(a)

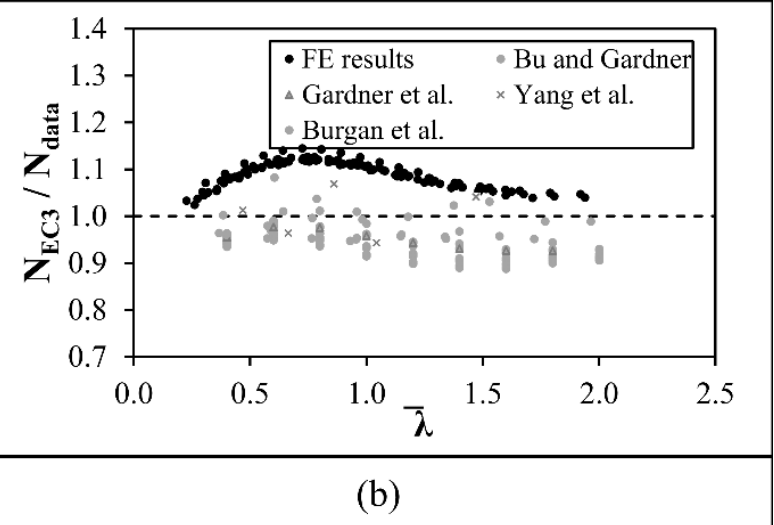

(b)

Figure 13. Results from (a) minor and (b) major axis flexural buckling data for austenitic stainless steel.

514 But, contrarily to what is said in [18], where the results showed that the current European buckling 515 curves for minor and major axis flexural buckling are applicable to austenitic grades welded with conventional procedures, this study indicates that the Eurocode provisions for austenitic columns are partially unsafe for both axes buckling. Only looking at the results for austenitic grades (Figure 13) which are available in the literature, they indicate that the Eurocode predictions are conservative for minor and major axis flexural buckling. However, the numerical results obtained in this research indicate that the Eurocode mostly provides slightly unsafe predictions for minor axis buckling and, mostly in the low slenderness range, for major axis buckling. Since the current European design rules consider a safety factor of 1.10 , it is quite important to assess if the currently adopted buckling curves are safe for austenitic grades.

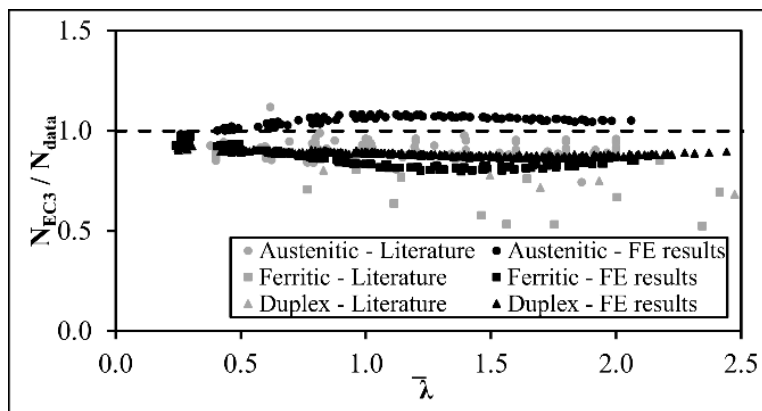

(a)

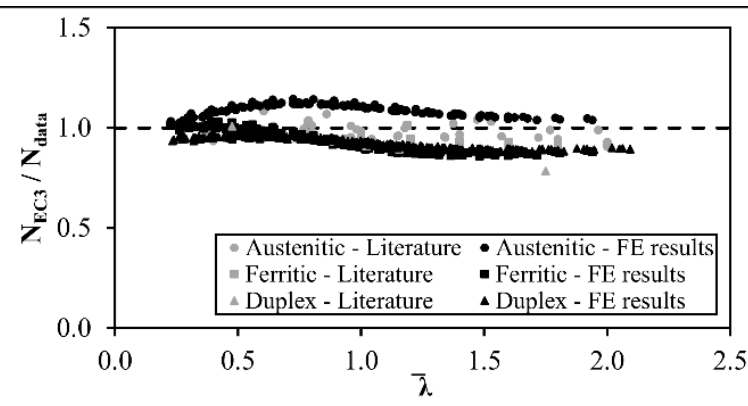

(b)

Figure 14. Results from (a) minor and (b) major axis flexural buckling data for all grades of stainless steel European predictions. 

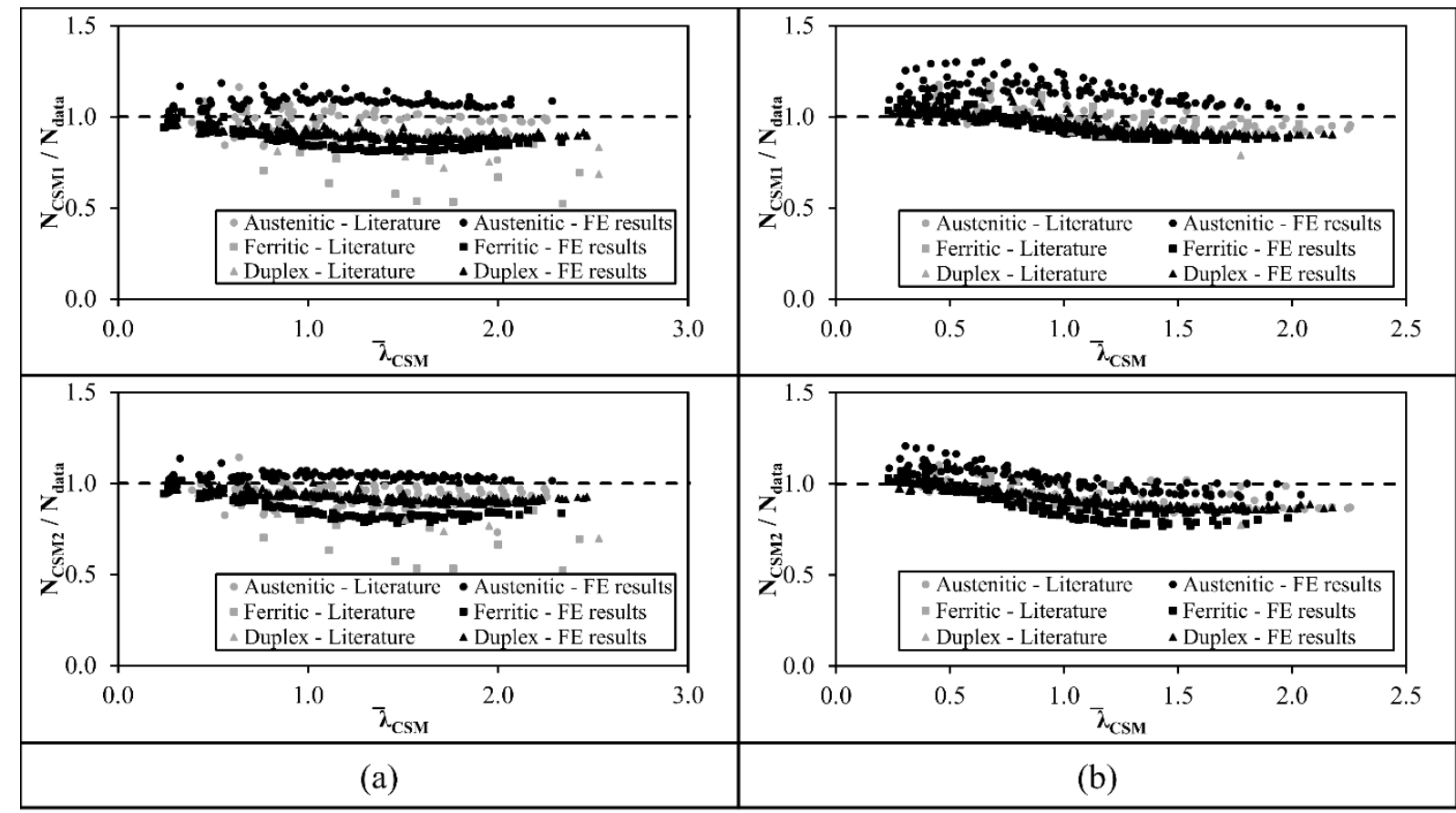

(a)

(b)

Figure 15. Results from (a) minor and (b) major axis flexural buckling data for all grades of stainless steel CSM1 and CSM2 predictions.

The FE data points have a slightly lower resistance compared to the test results from literature (Figure 14), due to which the predictions seem to be rather unconservative, mainly as a result of the overestimation of the global geometric imperfections by using $L / 1000$, instead of a smaller amplitude, for consistency with other studies. However, all results were also compared to the predictions using the CSM and the conclusions are in line with previous researches $[4,5,6]$. The CSM design approaches offer slightly improved strength predictions for medium slenderness for duplex and ferritic stainless steel with, in general, a marginally higher scatter. For ferritic and duplex grades, the strength is underestimated by CSM1 and CSM2 for all column slenderness values and particularly for higher ones. For austenitic columns, over the whole slenderness range, the minor and major axis buckling strength is generally overestimated by CSM1, but safe for CSM2.

Figure 16 shows the influence of the cross-sectional slenderness on the CSM1 buckling curves for each considered family. The results clearly show that columns with higher cross-sectional slenderness require higher CSM buckling curves. This complies with the findings of Ahmed et al. have who have already shown in [11] and [12] that CSM rules are dependent on the cross-sectional slenderness and have proposed techniques of taking this dependency into account. However, Figure 16 also shows that the CSM flexural buckling design rules necessitate even more to acknowledge the distinction in the behaviour between the stainless steel families.

Based on these results, it can be concluded that the most basic CSM, where the yield stress is replaced by the local buckling stress $f_{c s m}$ and the full section area is taken into account (CSM1), already yields encouraging results. The CSM2 approach takes into account the cross-sectional slenderness in the ratio 
between the equivalent imperfection amplitudes. CSM2 is more precise, however sometimes unsafe, compared to the CSM1 approach. It might be concluded that the CSM imperfection factor $\alpha_{\mathrm{csm}}$, as in CSM2, should be used for austenitic grades. However, for ferritic and duplex grades, the CSM1 approach with the codified buckling curves yields better results.

Both CSM approaches are promising and could lead to even more better results by, firstly, implementing the dependency on the stainless steel family and, secondly, by taking into account the dependency of the cross-sectional slenderness.
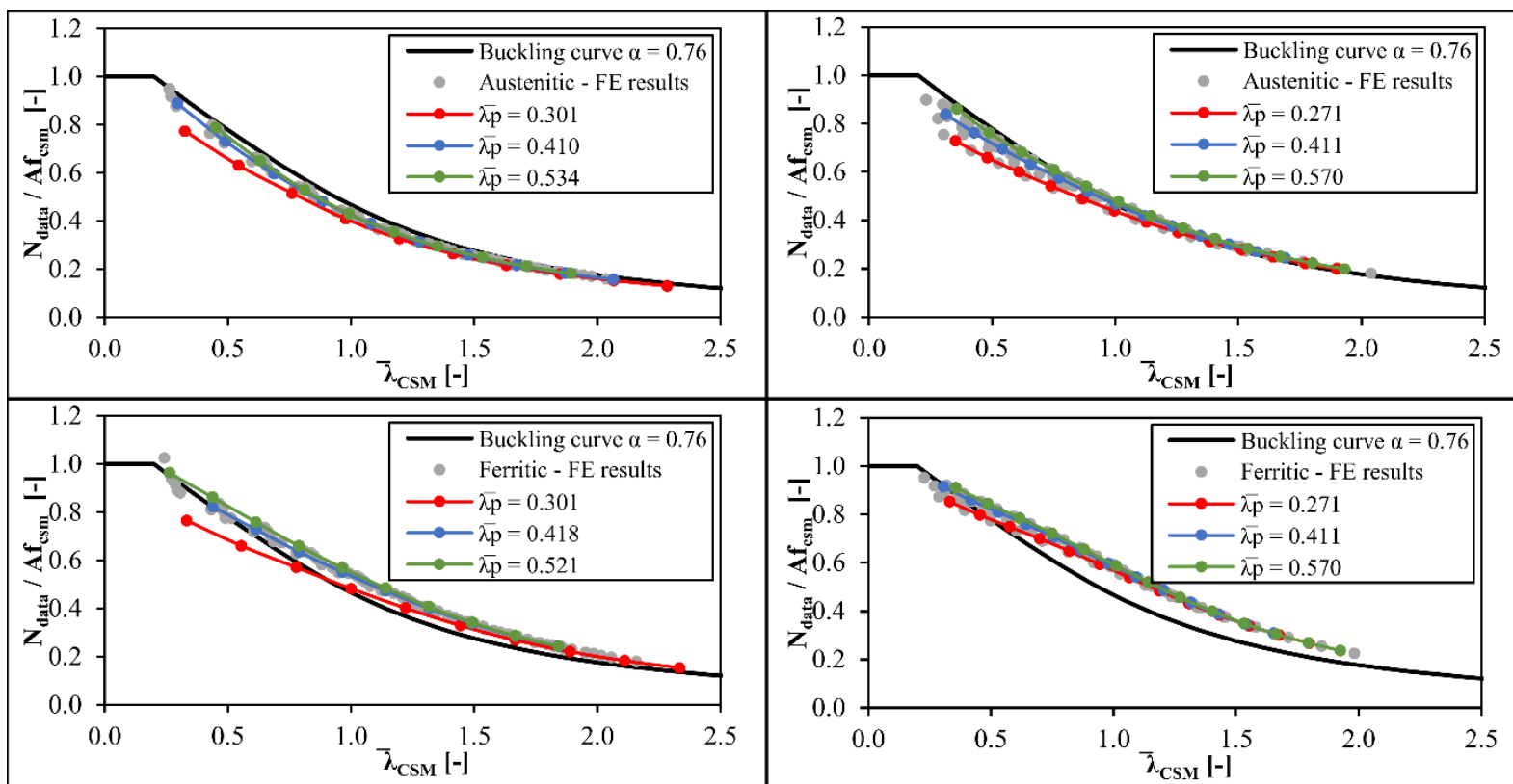

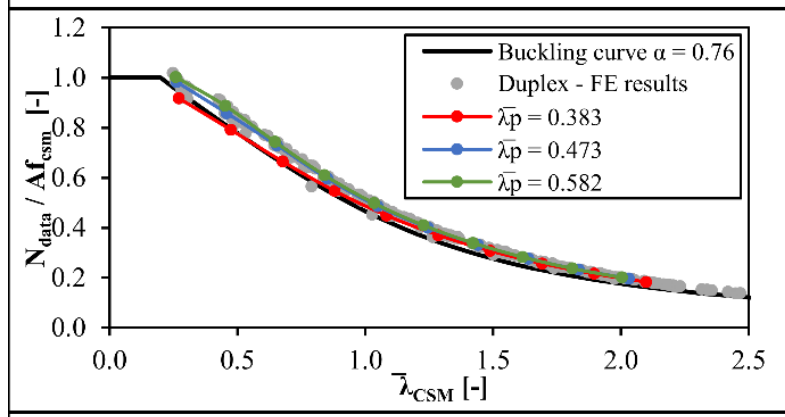

(a)

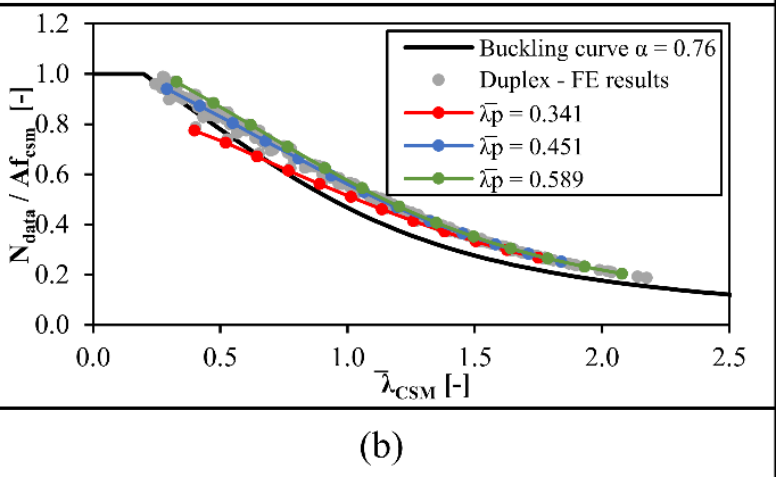

Figure 16. Influence of the cross-sectional slenderness on the CSM1 buckling curves.

The following reliability analysis was made according to the methodology proposed in [50], which agrees with the one in EN 1990:2002 annex D [51]. Firstly, the experimental resistance $r_{e}$ and the theoretical resistance $r_{t}$ are determined for each specimen. Equation D.7 to D.13 of EN 1990:2002 annex $\mathrm{D}$ [51] were employed to determine the correction factor $b$, the error term $\delta$ and the coefficient of variation on this error term $V_{\delta}$. Subsequently, the parameters $c$ and $d$ are determined using (25) and (26). 
$\mathrm{c}=\frac{\ln \left(\mathrm{N}_{\mathrm{b}, \mathrm{Rd}, 2} / \mathrm{N}_{\mathrm{b}, \mathrm{Rd}, 1}\right)}{\ln \left(\mathrm{f}_{\mathrm{y}, 2} / \mathrm{f}_{\mathrm{b}, 1}\right)}$

where $N_{b, R d, 1}$ and $N_{b, R d, 2}$ are obtained by considering a slight increase of the yield strength $\mathrm{f}_{\mathrm{y}}$ only.

$\mathrm{d}=\frac{\ln \left(\mathrm{N}_{\mathrm{b}, \mathrm{Rd}, 2} / \mathrm{N}_{\mathrm{b}, \mathrm{Rd}, 1}\right)-\mathrm{c} \ln \left(\mathrm{f}_{\mathrm{y}, 2} / \mathrm{f}_{\mathrm{b}, 1}\right)}{\ln \left(\mathrm{A}_{2} / \mathrm{A}_{1}\right)}$

where $N_{b, R d, 1}$ and $N_{b, R d, 2}$ are obtained by considering a slight increase of the cross-sectional area A only.

Knowing the parameters $c$ and $d$, the design resistance values $r_{d}$ have been obtained using Equation

568 Note that the formula for the parameter $V_{r t}$ is taken according to equation D.16b of EN 1990:2002 annex

D [51] instead of equation (23) of [50] where $V_{r t}$ is mentioned instead of $V_{r t}{ }^{2}$.

$$
\mathrm{V}_{\mathrm{rt}}^{2}=\left(\mathrm{cV}_{\mathrm{f}_{\mathrm{y}}}\right)^{2}+(\mathrm{dV} \mathrm{A})^{2}
$$

Where $V_{f_{y}}$ and $V_{A}$ are the coefficient of variation of the yield strength and the cross-sectional area respectively. In [50], the proposed coefficients of variation for $f_{y}$, based on statistical data on material and geometric parameters from stainless steel producers, for austenitic, ferritic and duplex grades are, $0.06,0.045$ and 0.03 respectively. The coefficient of variation of the geometric properties is considered equal to 0.05 , this value was utilized for stainless steel in the development of the AISC stainless steel design guide [52].

The analyses carried out in this paper follows the recommendations of [50] where the authors propose to use the overstrength factors in combination with an evaluation of the safety factor as the ratio of the nominal resistance $r_{n, i}$ to the design resistance $r_{d, i}$. This is done through Equation (28), where $\mathrm{f}_{\mathrm{y}, \mathrm{m}} / \mathrm{f}_{\mathrm{y}, \mathrm{nom}}$ is the overstrength factor. Lastly the partial safety factor for member resistance $\gamma_{\mathrm{M} 1}$ is determined by Equation (29).

$$
\begin{aligned}
& r_{d}^{\prime}=r_{d} \exp \left(c \ln \left(f_{y, m} / f_{y, n o m}\right)\right) \\
& \gamma_{M 1}=\frac{\sum r_{n, i}^{2}}{\sum r_{n, i} r_{d, i}^{\prime}}
\end{aligned}
$$

In the present analysis, the total test population was divided into appropriate sub-sets depending on the considered group of data. Since for Class 4 sections, the European formulations using the effective width properties is providing conservative results, it was decided to separate the Class 1, 2 and 3 sections from the Class 4 section for the evaluation of the safety factor. However, the number of data points for Class 4 sections is low since this concerns both austenitic and ferritic data for buckling around the minor axis 

(4) of EN 1990 Annex D [51] was then used.

588 The results of this analysis are presented in Table 12 and Table 13 for minor axis buckling and major 589 axis buckling respectively, where $N$ is the total number of data points (tests or FEM results), $b$ is the 590 mean experimental (or FEM)-to-model resistance ratio based on a least squares fit of the slope of the $r_{e i}$ 591 versus $\mathrm{r}_{t i}$ plot for each set of data, the coefficient of variation $\mathrm{V}_{\delta}$ of the error term $\delta_{i}=r_{e i} / b r_{t i}$ is used as 592 a measure of the variabilities of the predictions obtained from the resistance function, and $\gamma_{\mathrm{M} 1}$ is the 593 partial safety factor for the resistance against buckling.

Table 12. Reliability assessment results for minor axis buckling

\begin{tabular}{lllllllll}
\hline Family & Class & $\alpha$ & $\mathrm{N}$ & $\mathrm{b}$ & $\begin{array}{l}\mathrm{r}_{\mathrm{i}} / \mathrm{r}_{\mathrm{ei}} \\
\text { Mean }\end{array}$ & COV & $\mathrm{V}_{\delta}$ & $\gamma_{\mathrm{M} 1}$ \\
\hline All & 1 to 4 & & 588 & 1.013 & 1.02 & 0.100 & 0.100 & 1.28 \\
All, [13] excluded & 1 to 4 & & 575 & 1.012 & 1.02 & 0.092 & 0.087 & 1.23 \\
All & 1 to 3 & & 553 & 1.012 & 1.02 & 0.093 & 0.088 & 1.24 \\
Austenitic & 1 to 3 & & 223 & 0.961 & 1.10 & 0.106 & 0.099 & 1.24 \\
Ferritic & 1 to 3 & 0.49 & 108 & 1.022 & 0.96 & 0.029 & 0.031 & 1.03 \\
Duplex & 1 to 3 & & 222 & 1.020 & 0.99 & 0.036 & 0.038 & 1.10 \\
Austenitic & 4 & & 22 & 0.994 & 1.00 & 0.024 & 0.023 & 1.08 \\
Ferritic (only [13]) & 4 & & 13 & 1.285 & 0.76 & 0.125 & 0.168 & 1.27 \\
\hline All & 1 to 4 & & 588 & 1.108 & 0.91 & 0.086 & 0.097 & 1.16 \\
All, [13] excluded & 1 to 4 & & 575 & 1.108 & 0.91 & 0.077 & 0.083 & 1.12 \\
All & 1 to 3 & & 553 & 1.108 & 0.91 & 0.079 & 0.085 & 1.12 \\
Austenitic & 1 to 3 & 223 & 1.058 & 0.97 & 0.086 & 0.091 & 1.11 \\
Ferritic & 1 to 3 & 0.76 & 108 & 1.112 & 0.86 & 0.049 & 0.056 & 1.00 \\
Duplex & 1 to 3 & & 222 & 1.115 & 0.88 & 0.027 & 0.033 & 0.99 \\
Austenitic & 4 & & 22 & 1.131 & 0.88 & 0.021 & 0.024 & 0.95 \\
Ferritic (only [13]) & 4 & & 13 & 1.467 & 0.67 & 0.108 & 0.164 & 1.10 \\
\hline
\end{tabular}

Table 13. Reliability assessment results for major axis buckling

\begin{tabular}{lllllllll}
\hline Family & Class & $\alpha$ & $\mathrm{N}$ & $\mathrm{b}$ & $\begin{array}{l}\mathrm{r}_{\mathrm{t}} / \mathrm{r}_{\mathrm{ei}} \\
\text { Mean }\end{array}$ & & $\mathrm{V}_{\delta}$ & $\gamma_{\mathrm{M} 1}$ \\
& & & & & COV & & \\
\hline All & 1 to 3 & & 563 & 0.983 & 1.04 & 0.083 & 0.078 & 1.23 \\
Austenitic & 1 to 3 & & 215 & 0.914 & 1.09 & 0.102 & 0.096 & 1.27 \\
Ferritic & 1 to 3 & 0.34 & 115 & 0.974 & 1.00 & 0.043 & 0.043 & 1.09 \\
Duplex & 1 to 3 & & 233 & 0.993 & 1.00 & 0.033 & 0.033 & 1.10 \\
Austenitic & 4 & & 21 & 0.936 & 1.06 & 0.034 & 0.032 & 1.12 \\
\hline All & 1 to 3 & & 563 & 1.047 & 0.96 & 0.076 & 0.078 & 1.15 \\
Austenitic & 1 to 3 & & 215 & 0.973 & 1.02 & 0.090 & 0.092 & 1.19 \\
Ferritic & 1 to 3 & 0.49 & 115 & 1.033 & 0.93 & 0.056 & 0.060 & 1.07 \\
Duplex & 1 to 3 & & 233 & 1.058 & 0.93 & 0.030 & 0.033 & 1.04 \\
Austenitic & 4 & & 21 & 1.014 & 0.98 & 0.028 & 0.028 & 1.03 \\
\hline All & 1 to 3 & 0.76 & 563 & 1.147 & 0.86 & 0.079 & 0.091 & 1.10
\end{tabular}




\begin{tabular}{lllllllll}
\hline Family & Class & $\alpha$ & $\mathrm{N}$ & $\mathrm{b}$ & $\begin{array}{l}\mathrm{r}_{\mathrm{t}} / \mathrm{r}_{\mathrm{ei}} \\
\text { Mean }\end{array}$ & COV & $\mathrm{V}_{\delta}$ & $\gamma_{\mathrm{M} 1}$ \\
& & & & & & & \\
\hline Austenitic & 1 to 3 & & 215 & 1.066 & 0.91 & 0.085 & 0.096 & 1.10 \\
Ferritic & 1 to 3 & & 115 & 1.125 & 0.84 & 0.078 & 0.091 & 1.07 \\
Duplex & 1 to 3 & & 233 & 1.160 & 0.83 & 0.048 & 0.057 & 1.00 \\
Austenitic & 4 & & 21 & 1.141 & 0.87 & 0.034 & 0.039 & 0.94 \\
\hline
\end{tabular}

It is worth noting first that Table 2 and Table 3 were showing a certain conservativeness of the code based on the collected reference data. However, the numerical data presented here suggest otherwise for austenitic grades. Presently, the assessment revealed a higher scatter for austenitic grades and the comparison between the normalized FEM buckling loads and the codified ones confirms the initial assessment of the unsafe predictions in the intermediate and high slenderness range. But, although the mean of the EC3-to-FEM is slightly higher than 1.0, it is however closer to 1.0 than the same ratio considering the literature data. The numerical results show a consistent deviation between the austenitic grades behaviour and the ferritic and duplex ones, both for minor and major axis buckling. They also highlight the same distance between the numerical results and the test results coming from the literature, although, as demonstrated in Table 6, the present FEMs are able to accurately represent the conducted tests. It can be explained by the overstrength factor for austenitic grades (which equals 1.3), currently taken into account in the safety factor assessment. Indeed, the reliability assessment for austenitic grades in the sense of EN 1990 Annex D [51] suggests that the current buckling curves $d(\alpha=0.76)$ is appropriate for both axes. The authors recommend keeping $\alpha=0.76$ for austenitic grades without distinction of axis or Class.

It is wise to note at this stage that the test results reported data from Bredenkamp and Van Den Berg in [13] for ferritic built-up class 4 I-section columns are completely out of the series of points studied in this paper. This could be explained by the fact that the authors studied fabricated (welded) sections with, possibly, different geometrical and mechanical imperfections (residual stress) patterns. The authors indeed report that mechanical positioners were placed at intervals not exceeding $200 \mathrm{~mm}$, in order to prevent the flanges from distorting during the welding process. In order to prevent distortion of the section as a whole, the sections were stacked on top of each other and clamped together before final welding was done. This is affecting the evaluation of the safety factors, which is why, in Table 12, the results for ferritic grades is provided both with and without these values.

As stated in [19], the authors conclude that buckling curve $c$ is too conservative for the duplex grade EN 1.4462 and that lower residual stresses in duplex stainless steel sections, compared to austenitic equivalent, leads to higher strength. In [6] however, the authors mention that the behaviour of duplex stainless steel is similar to that of other stainless steel grades. Here, as previously mentioned, the numerical results show a consistent deviation between the austenitic grades and the ferritic and duplex ones, both showing similar trends for minor and major axis buckling. The reliability assessment demonstrates that an imperfection factor of 0.49 can safely be used in conjunction with a safety factor 
of 1.10 for both axes and both families. In fact, as indicated in [4] for hot finished RHS, CHS and EHS,

628 an imperfection factor equal to 0.34 could be adopted for major axis buckling.

629 This conclusion can be put in perspective with the shape of the current European buckling curves which

630 does not allow to closely follow the behaviour of stainless steel columns in the low slenderness range.

631 The current AS/NZS 4673:2001 [53] standard allows this to be taken into account for cold-formed

632 stainless steel members by introducing the non-linear factor $\eta$ depending on the stainless steel grade.

633 For the presented series of values, this would lead to a sensible difference in the intermediate slenderness

634 range for austenitic grade since the AS/NZS curves shift down due to the factor $\eta$.

\section{Conclusions}

636 The flexural buckling behaviour of stainless steel welded I-section columns was investigated in this

637 paper. A comprehensive numerical modelling investigation was carried out to generate the flexural

638 buckling performance data required for the assessment of the design methods for stainless steel welded

639 I-section columns. The flexural buckling design provisions in EN 1993-1-4 [3] and those developed for

640 the Continuous Strength Method were particularly investigated in detail. The current EN 1993-1-4 [3]

641 approach of recommending one buckling curve for all stainless steel grades was shown to be unsuitable

642 due to the differences in the stress-strain response and residual stresses of austenitic, duplex and ferritic

643 grades, which in turn influences the member stability response. Hence, new flexural buckling design

644 recommendations were made which include using (1) the flexural buckling curve with $\alpha=0.76$ for

645 austenitic stainless steel columns for both major and minor buckling axes and (2) the flexural buckling

646 curve with $\alpha=0.49$ for duplex and ferritic stainless steel columns for both major and minor buckling

647 axes. The suitability of these new recommendations was confirmed by rigorous reliability analysis in 648 accordance with Annex D of EN 1090 [39]. Overall, both studied CSM approaches were found to give

649 slightly improved strength predictions for stainless steel, but with marginally higher scatter, compared

650 to EN 1993-1-4 [3] and could lead to even more precise results by, for example, employing different

651 buckling curves to take into account the dependency on the stainless steel family and the cross-sectional 652 slenderness.

653 Conflicts of interest

$654 \quad$ None.

655 Acknowledgements

656 The Research Foundation Flanders (Belgium) is gratefully acknowledged for its financial support. 
[1] Euro Innox, "Design manual for structural stainless steel," 1994.

[2] ENV 1993-1-4, "Eurocode 3: Design of steel structures - Part 1.4: General rules - Supplementary rules for stainless steels," CEN, 1996.

[3] EN 1993-1-4, "Eurocode 3: Design of steel structures - Part 1-4: General rules - Supplementary rules for stainless steel," CEN, 2015.

[4] SCI/Euro Innox, "Design manual for structural stainless steel. Fourth edition.," 2017.

[5] H. Yuan, Y. Wang, Y. Shi and L. Gardner, "Stub column tests on stainless steel built-up sections," Thin-walled structures, vol. 83 (10), pp. 103-114, 2014.

[6] N. Saliba and L. Gardner, "Cross-section stability of lean duplex stainless steel welded I-sections," Journal of Constructional Steel Research, vol. 80, pp. 1-14, 2013.

[7] I. Arrayago, E. Real, E. Mirambell and L. Gardner, "The Continuous Strength Method for Stainless Steel Columns," in Proceedings of the 5th International Experts Seminar on Stainless Steel Structures, London, 2017.

[8] I. Arrayago, E. Real, E. Mirambell and L. Gardner, "The Continuous Strength Method for the design of stainless steel hollow section columns," Thin-Walled Structure, no. 154, 2020.

[9] EN 1993-1-1, "Eurocode 3: Design of steel structures - Part 1-1: General rules and rules for buildings," CEN, 2015.

[10] S. Afshan, O. Zhao and L. Gardner, "Standardised material properties for numerical parametric studies of stainless steel structures and buckling curves for tubular columns," Journal of Constructional Steel Research, no. 152, pp. 2-11, 2019.

[11] S. Ahmed, M. Ashraf and S. Al-Deen, "Empirical buckling curves for welded I-section columns produced from stainless steel," in EIghth International Conference on Advanced in Steel Structures, Lisbon, Portugal, 2015.

[12] S. Ahmed, S. Al-Deen and M. Ashraf, Design rules for stainless steel welded I-columns based on experimental and numerical studies, Canberra, ACT 2600, Australia: The University of New South Wales, 2018. 
[13] P. J. Bredenkamp and G. J. Van Den Berg, "The strength of stainless steel built-up I-section columns," Journal of Constructional Steel Research, Vols. 34 (2-3), pp. 131-144, 1995.

[14] The Steel Construction Institute, "Technical report 29: Tests on stainless steel beams and columns. SCI report no. RT/231," 1991.

[15] H. Yuan, Y. Wang, L. Gardner, X. Du and Y. Shi, "Local-overall interactive buckling behaviour of welded stainless steel I-section columns," Journal of Constructional Steel Research, vol. 111, pp. 75-87, 2015.

[16] L. Yang, M. Zhao, T. Chan, F. Shang and D. Xu, "Flexural buckling of welded austenitic and duplex stainless steel I-section columns," Journal of Constructional Steel Research, vol. 112, pp. 339-353, 2016.

[17] L. Gardner, Y. Bu and M. Theofanous, "Laser-welded stainless steel I-sections: Residual stress measurements and column buckling tests," Engineering Structures, vol. 127, pp. 536-548, 2016.

[18] Y. Bu and L. Gardner, "Finite element modelling and design of welded stainless steel I-section columns," Journal of Constructional Steel Research, 2019.

[19] B. Burgan, N. Baddoo and K. Gilsenan, "Structural design of stainless steel members - comparison between Eurocode 3, part 1.4 and test results," Journal of Constructional Steel Research, vol. 54, pp. 51-73, 2000.

[20] L. Yang, M. Zhao, D. Xu, F. Shang, H. Yuan, Y. Wang and Y. Zhang, "Flexural buckling behavior of welded stainless steel box-section columns," Thin-Walled Structures, vol. 104, p. 185-197, 2016.

[21] J. Becque and K. Rasmussen, "Numerical Investigation of the Interaction of Local and Overall Buckling of Stainless Steel I-Columns," Journal of Structural Engineering, vol. 135 (11), pp. 1349-1356, 2009.

[22] Hibbitt, Karlsson, Sorensen and Inc. ABAQUS, ABAQUS/Standard user's manual volumes I-III and ABAQUS CAE manual. Version 6.12, Pawtucket (USA), 2012.

[23] L. Gardner and D. Nethercot, "Numerical Modeling of Stainless Steel Structural Components A Consistent Approach,” Journal of Structural Engineering, no. 130(10), pp. 1586-1601, 2004.

[24] M. Ashraf, L. Gardner and D. Nethercot, "Finite element modelling of structural stainless steel cross-sections," Thin-Walled Structures, vol. 44, pp. 1048-1062, 2006. 
[25] M. Theofanous, T. Chan and L. Gardner, "Structural response of stainless steel oval hollow section compression members," Engineering structures, vol. 31, pp. 922-934, 2009.

[26] M. Theofanous and L. Gardner, "Testing and numerical modelling of lean duplex stainless steel hollow section columns," Engineering Structures, vol. 31, pp. 3047-3051, 2009.

[27] O. Zhao, B. Rossi, L. Gardner and B. Young, "Behaviour of structural stainless steel cross-sections under combined loading - Part II: Numerical modelling and design approach,” Engineering Structures, vol. 89, p. 247-259, 2015.

[28] S. Ahmed and M. Ashraf, "Numerical investigation on buckling resistance of stainless steel hollow members," Journal of Constructional Steel Research (136), pp. 193-203, 2017.

[29] B. Karabulut, B. Rossi , G. Lombaert and D. Debruyne , "Optimized design and life cycle cost analysis of a duplex welded girder bridge," in Life-Cycle Analysis and Assessment in Civil Engineering: Towards an Integrated Vision - Proceedings of the 6th International Symposium on Life-Cycle Civil Engineering, IALCCE 2018, 2019.

[30] H. Hill, "Determination of stress -strain relations from "offset" yield strength values. Technical Note No. 927," 1944.

[31] E. Mirambell and E. Real, "On the calculation of deflections in structural stainless steel beams: an experimental and numerical investigation," Journal of Constructional Steel Research, vol. 54, pp. 109-133, 2000.

[32] K. Rasmussen, "Full-range stress-strain curves for stainless steel alloys," Journal of Constructional Steel Research, vol. 2003, pp. 47-61, 2003.

[33] I. Arrayago, E. Real and L. Gardner, "Description of stress - strain curves for stainless steel alloys," Materials and Design, vol. 87, p. 540 -552, 2015.

[34] P. Hradil, A. Talja, E. Real, E. Mirambell and B. Rossi, "Generalized multistage mechanical model for nonlinear metallic materials," Thin-Walled Structures, vol. 63, pp. 63-69, 2013.

[35] E. Real, I. Arrayago, E. Mirambell and R. Westeel, "Comparative study of analytical expressions for the modelling of stainless steel behaviour," Thin-Walled Structures, vol. 83, pp. 2-11, 2014.

[36] S. Afshan and L. Gardner, "Experimental Study of Cold-Formed Ferritic Stainless Steel Hollow Sections," Journal of Structural Engineering, vol. 139, no. 5, pp. 717-728, 2013. 
[37] Y. Peng, J. Chu and J. Dong, "Compressive Behavior and Constitutive Model of Austenitic Stainless Steel S30403 in High Strain Range," Materials, 2018.

[38] N. Saliba and L. Gardner, "Experimental study of the shear response of lean duplex stainless steel plate girders," Engineering Structures, vol. 46, pp. 375-391, 2013.

[39] EN 1090-2, "Execution of steel structures and aluminium structures. Part 2: technical requirements for steel structures," CEN, 2011.

[40] EN 1993-1-5, "Eurocode 3: Design of steel structures - Part 1-5: plated structural elements.," CEN, 2006.

[41] R. Bjorhovde, "Deterministic and probabilistic approaches to the strength of steel columns," Lehigh University, Bethlehem (PA), USA, 1972.

[42] R. Dawson and A. Walker, "Post-buckling of geometrically imperfect plates," Journal of Structural Engineering, vol. 89, p. 75-94, 1972.

[43] BSK 99, Boverkets handbok om stalkonstruktioner, Swedish regulations for steel structures, Boverket, Karlskrona, Sweden, 1999.

[44] E. European Convention for Constructional Steelworks, Manual on stability of steel structures Part 2.2. Mechanical properties and residual stresses. 2nd ed., Brussels: ECCS Publication, 1976.

[45] R. Cruise and L. Gardner, "Residual stress analysis of structural stainless steel sections," Journal of Constructional Steel Research, vol. 64, p. 352-366, 2008.

[46] L. Gardner and R. Cruise, "Modeling of Residual Stresses in Structural Stainless Steel Sections," Journal of structural engineering, vol. 135(1), pp. 42-53, 2009.

[47] H. Yuan, Y. Wang, Y. Shi and L. Gardner, "Residual stress distributions in welded stainless steel sections," Thin-Walled Structures, vol. 79, pp. 38-51, 2014.

[48] EN 10088-2, "Stainless steels - Part 2: Technical delivery conditions for sheet/plate and strip corrosion resisting steels for general purposes," CEN, 2014.

[49] Z. Li and W. Schafer, "Twentieth International Specialty Conference on Cold-Formed Steel Structures," in Buckling analysis of cold-formed steel members with general boundary conditions using CUFSM: conventional and constrained finite strip methods, Saint Louis, Missouri, USA, November 3 \& 4, 2010. 
[50] S. Afshan, P. Francis, N. R. Baddoo and L. Gardner, "Reliability analysis of structural stainless steel design provisions," J. Construct. Steel Res., pp. 293-304, 114 (2015).

[51] EN 1990, "Eurocode - Basis of structural design,” CEN, 2002.

[52] AISC, Design Guide 27: Structural Stainless Steel, Chicago, Illinois, USA, 2013.

[53] "AS/NZS 4673:2001 - Cold-formed stainless steel structures. Australian - New Zealand Standard," Standards Australia, 2001.

659

660 